\title{
Antimicrobial hierarchically porous graphene oxide sponges for water treatment
}

\author{
Anya Filina, Nariman Yousefi, Mira Okshevsky, and Nathalie Tufenkji \\ Department of Chemical Engineering, McGill University, Montréal, Québec \\ H3A 0C5 Canada
}

\author{
Revised and resubmitted to \\ ACS Applied Bio Materials
}

*Corresponding author email: nathalie.tufenkji@mcgill.ca 


\begin{abstract}
Water treatment technologies based on graphene oxide (GO) sponges show promise due to their high surface area and versatile chemistry, yielding excellent adsorption affinity for different contaminants. However, the bacteria removal capacity and the intrinsic antimicrobial properties of GO sponges are not well understood. While GO has been successfully functionalized with antibiotics or metal biocides, these antimicrobials present cytotoxicity concerns. Natural antimicrobial agents such as antimicrobial enzymes, peptides and polymers hold promise in this respect due to their relatively low cost, biocompatibility and ability to readily functionalize GO by covalent bond formation with oxygen-containing functional groups. In this work, the antimicrobial enzyme lysozyme, antimicrobial peptide nisin, and antimicrobial polyamide $\varepsilon$-poly-L-lysine were used to covalently functionalize the surface of a hierarchically porous GO sponge. The antimicrobial activity of the functionalized material was demonstrated against two model organisms: the Grampositive B. subtilis and Gram-negative E. coli. The performance of the porous material in a simulated filtration context was evaluated using packed column experiments, and improved bacterial retention of both strains by the functionalized sponge was demonstrated. Furthermore, samples of spent sponge after filtration were evaluated with a membrane integrity assay demonstrating antimicrobial activity in a continuous flow mode.
\end{abstract}

Keywords: lysozyme, nisin, E-poly-L-lysine, antimicrobial, adsorption, filter 


\section{Introduction}

Ensuring reliable access to potable water is a global challenge. Population growth, urbanization, and increased frequency of extreme weather events create stress on our water systems. ${ }^{1-2}$ Graphene oxide (GO) has shown potential as an adsorptive material for water treatment applications with the capacity to remove a variety of organic dyes, metals, and model pharmaceuticals. ${ }^{3-4}$ Furthermore, GO nanosheets can self-assemble into hydrogel networks or sponges that allow for easy separation of the filter material from the water stream after treatment. ${ }^{5-10}$ We recently developed a robust and hierarchically porous GO sponge (sp-GO) by reduction with L-ascorbic acid (vitamin C) that showed promise for the removal of various classes of water contaminants. ${ }^{11}$ While GO based water treatment technologies have shown promise in small lab-scale systems, the implementation of these technologies in commercial products is hindered somewhat by the high cost and low yield of the GO manufacturing process. ${ }^{10}$ However, recent interest in applying GO to various material contexts such as in electronic applications ${ }^{12-13}$ may be expected to lead to economies of scale in the future. ${ }^{10}$

While the use of GO sponges for the removal of chemical contaminants by adsorption has been studied, the removal of bacteria by GO and GO-based systems is not well understood. GO nanosheets are reported to exhibit antimicrobial properties through both oxidative stress ${ }^{14-16}$ and membrane damage ${ }^{17-20}$ mechanisms, although the primary antimicrobial mechanism and the extent of bactericidal potency remain unclear. ${ }^{21-22}$ While some proposed technologies rely on the intrinsic antimicrobial properties of GO in the context of water treatment and disinfection, ${ }^{23-24}$ improved disinfection efficacy may be achieved in composite systems incorporating potent antimicrobial metals, ${ }^{25-26}$ salts, ${ }^{27}$ and peptides. ${ }^{28-30}$

Natural antimicrobial agents such as antimicrobial enzymes, peptides and polymers are promising in this context due to their biocompatibility, relatively low cost, and low toxicity. The objective of this work is to impart antimicrobial properties to the sp-GO by functionalizing it with natural antimicrobial agents including an enzyme (lysozyme), peptide (nisin) and polyamide ( $\varepsilon$-poly-L-lysine). Lysozyme (LYS) catalyzes the cleavage of peptidoglycan, the primary structural component found in bacterial cell wall $s^{31}$ and it has been successfully immobilized by electrostatic interactions and covalent 
coupling to form nanocomposites with GO. ${ }^{32-35}$ The antimicrobial peptide nisin (NIS) has been coupled to GO to produce a nanocomposite based porous membrane for water disinfection. ${ }^{29}$ The cationic polyamide $\varepsilon$-poly-L-lysine (PLL) has broad spectrum antimicrobial activity against both Gram-positive and Gram-negative bacteria species. ${ }^{36-37}$ It has been studied with GO as a nanocomposite for sensing and biomedical applications but has not yet been studied in the context of GO-based 3D porous structures for water treatment. ${ }^{38-41}$ All three of the selected antimicrobial agents are relatively low cost, contain functional groups suitable for covalent coupling with the GO surface, and have no reported evidence of cytotoxicity to mammalian cells. In fact, all three of the antimicrobial agents are commercially available, are generally recognized as safe (GRAS designated) and are used as additives in food preservation and pharmaceutical applications. ${ }^{42-44}$ As a result, a novel antimicrobial material system incorporating lysozyme, nisin, or PLL is expected to be economically feasible and to have no harmful effects to human health.

In this work, we developed antimicrobial GO nanosheets and sponges by covalently bonding LYS, NIS and PLL to their surfaces. A systematic approach was taken to develop and characterize the materials. Antimicrobial assays with the antimicrobial agents alone were undertaken to assess their activity against the model Gram-positive Bacillus subtilis 6633 and the model Gram-negative Escherichia coli K12. Antimicrobial agents were immobilized on both GO nanosheets and the sp-GO material by EDC/NHS coupling chemistry and functionalization was confirmed by X-ray photoelectron spectroscopy (XPS), Fourier Transform Infrared Spectroscopy (FTIR), zeta-potential measurements and scanning electron microscopy (SEM). Due to the similar chemistry of the three selected antimicrobial agents, it was possible to compare the success of functionalization. Subsequently, the antimicrobial efficacy of functionalized GO nanosheets was evaluated by assessing impact on cell growth and cell membrane integrity. The antimicrobial activity of functionalized spGO was evaluated by membrane integrity assay. While column transport experiments have been used to study bacterial transport in sand and other granular media ${ }^{45-49}$ and gravity filtration experiments with graphene based networks have been conducted, ${ }^{26-27,50}$ dynamic bacterial transport in porous GO networks has not previously been studied. In the context of water treatment, dynamic measurements allow for an evaluation of filter performance over time and provide insights on the nature of bacterial 
interactions with the filter media. To this end, performance of the functionalized sp-GO was evaluated in continuous flow (packed column) systems by measuring bacterial removal and cell death within the sponge after use.

\section{Materials and methods}

\subsection{Material Synthesis}

\subsubsection{Graphene Oxide (GO) Synthesis}

Graphene oxide was synthesized by a modified Hummer's method. ${ }^{51-52}$ Briefly, graphite (natural graphite, Ausbury Mills) was expanded at $1050^{\circ} \mathrm{C}$ for 15 s. $0.5 \mathrm{~g}$ of expanded graphite was suspended in $100 \mathrm{~mL}$ of concentrated sulfuric acid (Fisher) and reacted with $5 \mathrm{~g}$ of potassium permanganate (Sigma Aldrich) for $24 \mathrm{hr}$ with stirring at $200 \mathrm{rpm}$. Reaction temperature was maintained at $45^{\circ} \mathrm{C}$ in a water bath. Following the reaction, the reaction flask was transferred to an ice bath and $125 \mathrm{~mL}$ of a 4:1 solution of deionized water (DI): hydrogen peroxide (Fisher) was slowly added while stirring for a total reaction time of $30 \mathrm{~min}$. The mixture was then transferred to centrifuge tubes and was washed through multiple centrifugation steps. Each wash consisted of decantation of supernatant, resuspension, and centrifugation at a maximum relative centrifugal force (rcf) of $20,000 \mathrm{~g}$. A total of 3 acid wash cycles were performed in $10 \%$ hydrochloric acid (Fisher) solution, followed by 5 water wash cycles in DI water. The final GO dispersion with a concentration of $4 \mathrm{mg} \mathrm{mL}^{-1}$ is stable and may be stored at room temperature.

\subsubsection{Graphene Oxide Sponge (sp-GO) Synthesis}

The hierarchically porous sp-GO were prepared according to previously described methods ${ }^{11}$ and a schematic is shown in Figure S1b. Briefly, $6 \mathrm{~g}$ of vitamin C (L-ascorbic acid, Fisher) was added to 40 $\mathrm{mg}$ of GO in glass vials and mixed by vortexing. The vials were subsequently held in a water bath at $95^{\circ} \mathrm{C}$ for one hr. Vortexing was performed after 2, 5, and $15 \mathrm{~min}$ to ensure homogenous dispersion and then the vials were left undisturbed for the remainder of the hr. The self-assembled, partially reduced GO sponges were washed with large amounts of DI water to remove excess vitamin C. 


\subsubsection{Functionalization of GO Nanosheets and sp-GO with Antimicrobial Agents}

The surface of the GO nanosheets or sp-GO material was functionalized with antimicrobial agents by amide bond formation between carboxyl groups on the GO and sp-GO surfaces, and amino groups on nisin (Sigma Aldrich), lysozyme (ThermoFisher), and $\varepsilon$-poly-L-lysine (Carbosynth) based on previously reported methods. ${ }^{29-30}$ Due to the presence of amino groups on all three of the antimicrobial agents, carbodiimide coupling chemistry could be used for all of the functionalization processes which allowed for comparison of the functionalized materials. Functionalization of GO nanosheets by electrostatic interactions was also attempted but was found to be less effective than covalent functionalization (data not shown). Functionalization was first studied on the colloidal GO nanosheet system, and a schematic of the functionalization process is shown in Figure S1a. GO surface carboxyl groups were activated by reacting with the coupling agents 1-ethyl-3(3dimethylaminopropyl)carbodiimide.HCl (EDC, $25 \mathrm{mg} / \mathrm{mL}$ ) (Sigma Aldrich) and Nhydroxysuccinimide (NHS, $50 \mathrm{mg} / \mathrm{mL}$ ) (Sigma Aldrich) for $30 \mathrm{~min}$. Antimicrobial agents were subsequently added in varying weight ratios under stirring. Reaction was allowed to proceed for 24 hr. Excess reagents were removed by washing with DI water. Functionalized GO nanosheets were washed three times by repeating cycles of centrifugation at $20,000 \mathrm{~g}$, decantation, and re-suspension in DI. Functionalized nanosheets are stable and could be stored suspended in phosphate buffered saline (PBS, ThermoFisher) in the refrigerator for several weeks.

After successful functionalization of the GO nanosheets was confirmed, a post-synthesis functionalization of the sponges (sp-GO) was undertaken as shown in Figure S1b. A post-synthesis functionalization process was chosen in order to eliminate potential damage to the antimicrobial agents which could occur due to the low $\mathrm{pH}$ and high temperature used during sponge synthesis. EDC/NHS reaction chemistry is relatively mild, being performed at near neutral $\mathrm{pH}$ and ambient temperature and therefore it is useful in this context. The functionalization of the sponges was performed under the same concentration, time, temperature and $\mathrm{pH}$ conditions as described above for the GO nanosheets. Functionalized sp-GO was washed 10 or more times with $50 \mathrm{~mL}$ of DI water for each wash, and vacuum filtration was used to separate the sponge from the aqueous phase. After the final 
wash step, functionalized sp-GO sponges were immersed in PBS and could be stored in the refrigerator for several weeks.

\subsection{Material Characterization}

The zeta-potential of the functionalized nanosheets $(0.04 \mathrm{mg} / \mathrm{mL})$ was measured using a ZetaSizer Nano ZS, Malvern Instruments at $25^{\circ} \mathrm{C}$ to understand impact of functionalization on surface charge. The surface chemistry of the functionalized materials was studied by X-ray photoelectron spectroscopy (XPS, Thermo Scientific K-Alpha) using a monochromatic Al $\mathrm{K}_{\alpha} \mathrm{X}$-ray source in $10^{-8}$ mbar vacuum. Thin films of GO nanosheets and free dissolved antimicrobial agents were prepared by drop casting onto aluminum foil and drying under ambient conditions. Sponge samples were freeze dried at -80 ${ }^{\circ} \mathrm{C}$ for $24 \mathrm{hr}$. Single survey scans with pass energy of $200 \mathrm{eV}$ were performed to analyze the elemental composition, and to confirm functionalization. High resolution scans with pass energy of $50 \mathrm{eV}$ were performed of the $\mathrm{C}_{1 \mathrm{~s}}$ and $\mathrm{N}_{1 \mathrm{~s}}$ peaks. Five scans were performed for all high resolution scans, and single scans in triplicate were performed for the survey scan measurements. XPSPEAK 4.1 software was used to de-convolute high resolution $\mathrm{C}_{1 \mathrm{~s}}$ and $\mathrm{N}_{1 \mathrm{~s}}$ peak profiles into constituent peaks according to methods previously employed for the deconvolution of high resolution scans of graphene based material. ${ }^{11,40,51-}$ 54 Briefly, full width half maximum (FWHM) values were constrained at $0.8-1.4 \mathrm{eV}$, and Gaussian/Lorenzian ratio was constrained between 10-30\%. $\mathrm{C}_{1 \mathrm{~s}}$ peak binding energies of $-284.3 \mathrm{eV}$, $-285.6 \mathrm{eV},-286.6 \mathrm{eV},-287.7 \mathrm{eV}$ and $-289 \mathrm{eV}$ were identified as $\mathrm{sp}^{2}$ carbon $(\mathrm{C}=\mathrm{C}), \mathrm{sp}^{3}$ carbon $(\mathrm{C}-$ $\mathrm{C})$, hydroxyl $(\mathrm{C}-\mathrm{OH})$, carbonyl/ epoxide $(\mathrm{C}=\mathrm{O} / \mathrm{C}-\mathrm{O}-\mathrm{C})$, and carboxyl $(\mathrm{COOH})$, respectively. $\mathrm{N}_{1 s}$ binding energies of $-399 \mathrm{eV},-400 \mathrm{eV}$, and $-401.5 \mathrm{eV}$ were identified as amine, amide and N-O or protonated nitrogen species, respectively. Fourier-Transform Infrared Spectroscopy (ATR-FTIR, Perkin Elmer Spectrum Two) spectra were collected from thin-film drop cast samples of the antimicrobial agents and functionalized nanosheets, and freeze-dried sponge samples. Spectra were obtained in the range of $400-4000 \mathrm{~cm}^{-1}$.

The impact of functionalization on pore structure of the sponges was evaluated by scanning electron microscopy (SEM, Hibachi SU 3500) with secondary electrons accelerated at $5 \mathrm{kV}$. Sponge samples 
were cut with a razor blade to expose the interior structure and were dried by lyophilization at $-80^{\circ} \mathrm{C}$ for $24 \mathrm{hr}$. Samples were secured to supports using carbon tape. Sputter coating with a conductive alloy was not necessary prior to imaging, as the partially reduced GO is sufficiently conductive.

\subsection{Evaluation of Antimicrobial Activity}

\subsubsection{Bacteria and Culture Conditions}

Non-pathogenic model organisms were selected for antimicrobial activity assays: Gram-negative $E$. coli K12, and Gram-positive B. subtilis ATCC 6633. Bacteria were stored in frozen glycerol stock at $80^{\circ} \mathrm{C}$. Bacteria were streaked onto Luria broth (LB) agar (Fisher) plates and incubated overnight at $35^{\circ} \mathrm{C}$. Plates were stored at $4{ }^{\circ} \mathrm{C}$ for no more than two weeks. To prepare pre-cultures for antimicrobial assays, a single colony was selected using a sterile loop and used to inoculate $10 \mathrm{~mL}$ of sterile LB (Fisher) nutrient broth with a concentration of $20 \mathrm{~g} / \mathrm{L}$. For continuous flow experiments, a larger volume $(120 \mathrm{~mL})$ of nutrient broth was required. Pre-cultures were incubated overnight at $35^{\circ} \mathrm{C}$ under agitation at $130 \mathrm{rpm}$. For experiments performed on cells in mid-exponential phase, the culture was diluted to an $\mathrm{OD}_{600}=0.05$ and incubated again at $130 \mathrm{rpm}$ at $35^{\circ} \mathrm{C}$ for $4 \mathrm{hr}$ for $E$. coli and $6 \mathrm{hr}$

for B. subtilis. Prior to experiments in PBS, cells were washed 3 times, centrifuged $(3,000 \mathrm{~g}, 5 \mathrm{~min})$ and resuspended in PBS.

\subsubsection{Growth Inhibition Assay}

For measurement of bacterial growth curves, a pre-culture was diluted with LB nutrient broth to an $\mathrm{OD}_{600}=0.05$ and combined with the antimicrobial agent of interest in 96-well micro-titer plates. Each experiment was performed in 3 biological replicates with at least 3 technical replicates for each biological replicate. As free NIS and LYS did not show evidence of inhibitory activity against E. coli, they were not tested after immobilization on GO nanosheets. Growth was tracked by optical density measurements $\left(\mathrm{OD}_{600}\right)$ using the Tecan Infinite M200 Pro microplate reader (Tecan Group Ltd., Switzerland). The plate was incubated at $34.5-35.5^{\circ} \mathrm{C}$. Prior to each reading, the plate was agitated in rotational mode for $1000 \mathrm{~s}$. The minimum inhibitory concentration (MIC) is considered to be the lowest concentration tested with complete growth inhibition after $24 \mathrm{hr}$. The optical density $\left(\mathrm{OD}_{600}\right)$ 
at each time point was normalized according to methods previously reported for growth assays of nanoparticles ${ }^{5}$ by subtracting the baseline optical density value at the initial time point $(t=0)$ from each measured optical density value. The mid-exponential phase growth rate was calculated by determining the slope of the linear portion of the semi-logarithmic plot, and lag time was determined as the intersection of the linear regressions of the exponential and lag portions of the semi-logarithmic growth profiles. ${ }^{56-57}$

\subsubsection{Membrane Integrity Assay}

Bacterial cells harvested in mid-exponential growth phase were washed three times to remove nutrients by centrifuging at $3000 \mathrm{~g}$ for $5 \mathrm{~min}$ and re-suspending in PBS (Sigma). After the final wash, the bacteria were re-suspended in PBS to achieve a final $\mathrm{OD}_{600}=1$.

For Live/Dead experiments with GO nanosheets, bacteria were incubated for $15 \mathrm{hr}$ with nanosheets $(0.250 \mathrm{mg} / \mathrm{mL})$ in PBS buffer $(200 \mu \mathrm{L}$ total volume) in 96-well untreated microscopy plates (IBIDI). For Live/Dead experiments with sponges, $200 \mu \mathrm{L}$ of bacteria were incubated with small samples $(0.125$ g) of hydrated sponges in 96-well untreated microscopy plates (IBIDI). In this study, it was not intended to compare the antimicrobial activity of the functionalized GO nanosheets and the functionalized sp-GO, therefore, the mass of GO or antimicrobial agent was not matched in these experiments. Therefore, the results of these experiments cannot be compared directly.

Following incubation, all of the samples were stained using the Live/Dead BacLight ${ }^{\oplus}$ (Molecular Probes) viability kit. The green fluorescent stain (SYTO-9) permeates cell membranes and stains all bacteria, while the red fluorescent stain (propidium iodide) only penetrates cells with compromised membranes. Samples were imaged using a Zeiss LSM800 confocal laser scanning microscope equipped with a Plan-Apochromat oil-immersion $63 \times$ objective. Three biologically distinct replicates were prepared and a total of 30-50 images were obtained for each condition. Z-stacks were compiled with Zen Black imaging software (Zeiss, version 2.3). Image analysis was performed using ImageJ software. Briefly, the color channels in each image were split and the pixel area of red fluorescence and total fluorescence was measured. The percentage of compromised cells was calculated as the ratio of red biomass to total biomass. 


\subsection{Removal of Bacterial Contaminants by sp-GO in Continuous Flow}

A $1 \mathrm{~cm}$ diameter glass column (GE Life Sciences) was used for continuous flow experiments. A Nylon membrane (Spectrum Laboratories, mesh opening $70 \mu \mathrm{m}$ ) was laid onto the bottom end piece of the glass column. Next, a layer of clean acid-washed ${ }^{45}$ quartz sand (2 g, mesh size 50/70) was added. A water saturated sp-GO sample ( $40 \mathrm{mg} \mathrm{GO}$ ) was crushed using a metal spatula and wet-packed into the column filled with electrolyte solution. All tubing in the column apparatus were purged of air and filled with electrolyte during the column packing process. An electrolyte flowrate of $0.4 \mathrm{~mL} / \mathrm{min}$ was used and the column was allowed to equilibrate until constant and low background absorbance values were attained. A UV-vis spectrophotometer (Agilent HP8453) with a $30 \mu \mathrm{L}$ flow cell was used to monitor the effluent bacteria concentration at $600 \mathrm{~nm}$ wavelength. In addition to absorbance measurements, aliquots were collected at $(t=0,60,120,180 \mathrm{~min})$. Effluent samples were serially diluted and plated using the drop-plate colony forming units (CFU) method. ${ }^{58} 0.1 \times$ PBS buffer having an ionic strength of $16 \mathrm{mM}$ was used as the electrolyte. Samples of spent filter material were collected after 180 min of operation, and stained using the BacLight ${ }^{\circ}$ Live/Dead kit. Confocal laser scanning microscopy (Zeiss LSM800) was used to image the bacteria present in the sponge material after use, in order to determine antimicrobial performance of the sponge material in continuous flow operation.

\section{Results and Discussion}

\subsection{Functionalization of GO nanosheets and sponges with antimicrobial agents}

The selected antimicrobial agents all contain amine groups that can be exploited for functionalization by amide bond formation with carboxyl groups on the GO nanosheet and sp-GO surface. The amide bond is stable due to its covalent nature and the resonance between the nitrogen electron pair and the adjacent carbonyl group; the amide bond stability has been exploited for the functionalization of graphene oxide and polymer materials. ${ }^{59-60}$ The antimicrobials were first immobilized on the GO nanosheets, the building blocks of the sponge. Zeta-potential $(\zeta)$ of the different nanosheets was measured to compare the surface charge of pristine GO and functionalized GO (Table S1). The zeta- 
potential of GO $(0.04 \mathrm{mg} / \mathrm{mL})$ was $-48 \pm 3 \mathrm{mV}$. GO has a high density of oxygen-containing groups that renders the surface negatively charged overall. Functionalized GO shows an increase in zetapotential with a measured $(\zeta)$ of $-27 \mathrm{mV} \pm 1,-42 \mathrm{mV} \pm 1$, and $-5 \mathrm{mV} \pm 2$ for the GO/NIS, GO/LYS and GO/PLL, respectively. Since all of the antimicrobial agents carry a net positive charge, an increase in surface charge is preliminary evidence of successful functionalization of the GO nanosheets. XPS analysis was performed to confirm functionalization of GO nanosheets by EDC/NHS coupling chemistry and to determine the elemental composition of the functionalized GO nanosheets. While no nitrogen content was detected in the pristine (non-functionalized) GO samples, after functionalization, 6-10 at $\%$ nitrogen was detected (Table S2). Furthermore, when the quantity of NIS and LYS was doubled during the functionalization reaction, the at $\%$ nitrogen also approximately doubled, suggesting consistent and successful immobilization by EDC/NHS coupling chemistry (Table S2).

Having demonstrated successful functionalization of the GO nanosheets, functionalization of sp-GO was undertaken. A post-synthesis functionalization process was used to avoid potential damage to the antimicrobial agents by the low $\mathrm{pH}$ and elevated temperature $\left(95^{\circ} \mathrm{C}\right)$ used during sponge synthesis. The sponge network is formed by a reduction process where vitamin $\mathrm{C}$ is used both as a soft template and reducing agent. ${ }^{11}$ During sp-GO self-assembly, the GO nanosheets undergo partial chemical reduction by vitamin $\mathrm{C}$, which potentially decreases the number of carboxyl groups available for subsequent functionalization. Therefore, while functionalization was demonstrated in the GO nanosheet system, successful functionalization in the physically and chemically distinct sp-GO material is not guaranteed.

Immobilization of the antimicrobials on the as-synthesized sponge (sp-GO) was confirmed by XPS; and while no nitrogen was detected in sp-GO controls, -5-6 at $\%$ nitrogen was detected in the functionalized sp-GO samples (Table 1). It is relevant to note, however, that for the same 1:1 reaction ratio immobilized on the GO nanosheets, the atomic composition of nitrogen was $-10-11 \%$ (Table S2). This suggests that immobilization on the sponge is in fact less effective than on the nanosheets, as expected due to the partial reduction of oxygen-containing groups during sponge synthesis. 
Nonetheless, the XPS data confirms that immobilization of antimicrobials on the sp-GO material was achieved.

Table 1. Atomic composition of functionalized sponges (sp-GO) for a reaction ratio of 1:1.

\begin{tabular}{cccc} 
Material & $\mathrm{C}_{1 \mathrm{~s}}$ & $\mathrm{O}_{1 \mathrm{~s}}$ & $\mathrm{~N}_{1 \mathrm{~s}}$ \\
\hline sp-GO & $84.8 \pm 0.5 \%$ & $15.2 \pm 0.4 \%$ & n.d. $^{*}$ \\
\hline sp-GO/NIS & $77.6 \pm 2.6 \%$ & $16.9 \pm 1.5 \%$ & $5.5 \pm 1.4 \%$ \\
\hline sp-GO/LYS & $77.9 \pm 2.6 \%$ & $16.1 \pm 2.2 \%$ & $6.0 \pm 0.7 \%$ \\
\hline sp-GO/PLL & $79.8 \pm 0.65 \%$ & $12.1 \pm 0.4 \%$ & $8.2 \pm 0.2 \%$ \\
\hline${ }^{*}$ n.d.: none detected & & &
\end{tabular}

Deconvolution of the XPS $\mathrm{C}_{1 \mathrm{~s}}$ and $\mathrm{N}_{1 \mathrm{~s}}$ peaks was performed to provide insight into the nature of the carbon and nitrogen bonding in the functionalized sponges. Representative de-convoluted spectra for GO, sp-GO sp-GO/PLL are presented in Figure 1. The de-convoluted peak spectra of all other conditions can be found in Figures S2 and S3. 

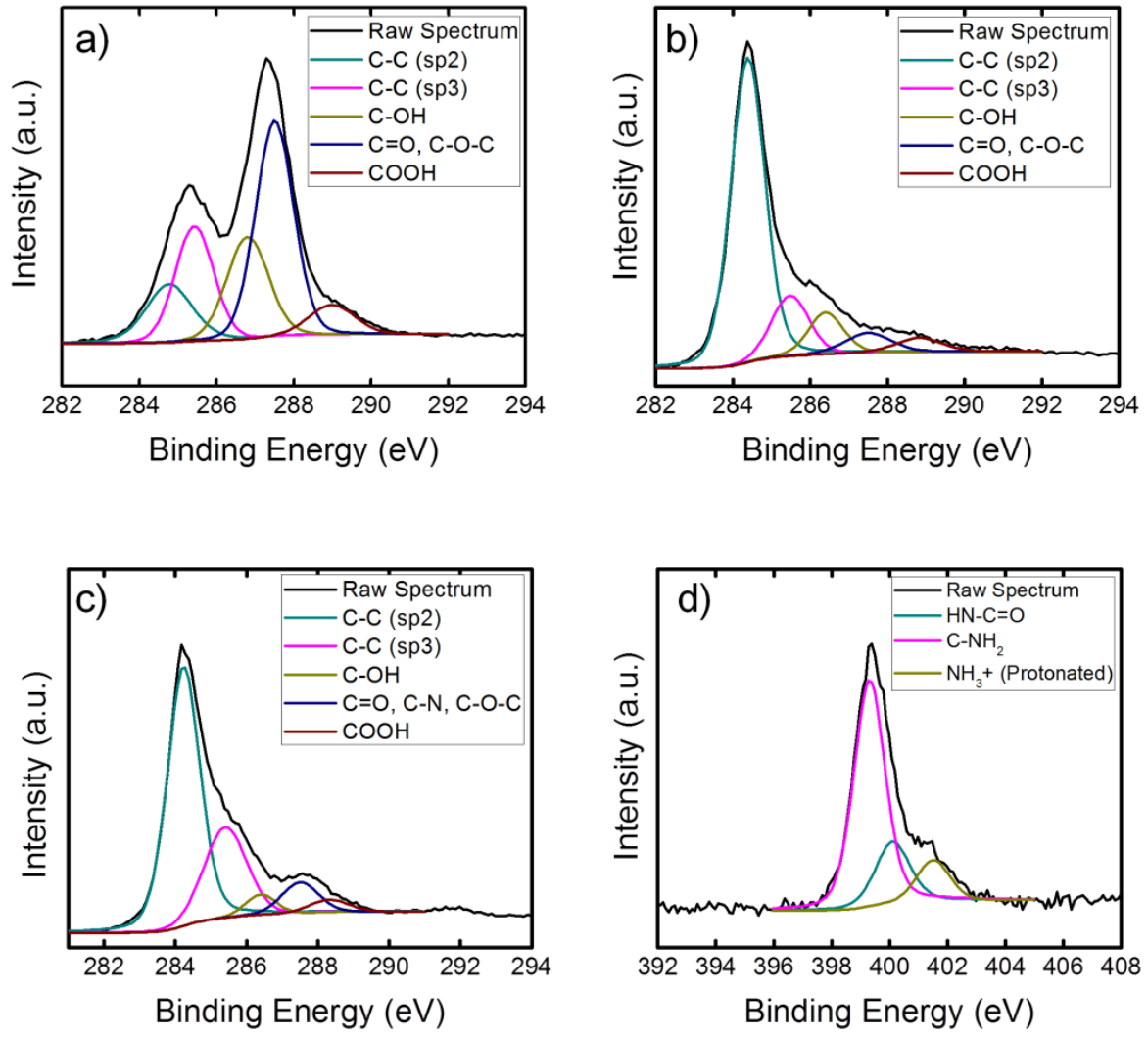

Figure 1. Deconvoluted XPS spectra of a) $G O C_{1 s}$, b) sp-GO $\left.C_{1 s}, c\right) s p-G O / P L L ~ C_{1 s}$, d) sp-GO/PLL $\mathrm{N}_{1 s}$ peaks.

Peak positions and integrated area-based percentages are presented in Table 2. A characteristic $\mathrm{GO}_{1 \mathrm{~s}}$ peak profile is seen in the GO control (Figure 1a) with peaks at approximately $284.3 \mathrm{eV}\left(\mathrm{sp}^{2}\right.$ carbon, $\mathrm{C}=\mathrm{C}), 285.6 \mathrm{eV}\left(\mathrm{sp}^{3}\right.$ carbon, $\left.\mathrm{C}-\mathrm{C}\right), 286.6 \mathrm{eV}$ (hydroxyl, C-OH), $287.7 \mathrm{eV}$ (carbonyl, $\mathrm{C}=\mathrm{O}$ ), and $289 \mathrm{eV}$ (carboxyl, $\mathrm{COOH})$. The epoxide $(\mathrm{C}-\mathrm{O}-\mathrm{C})$ peak has been assigned to overlap with the carbonyl peak $(287.7 \mathrm{eV})$ due to the large chemical shift into the $\mathrm{C}=\mathrm{O}$ emission range which has been reported for graphene oxide materials. ${ }^{54,61-62}$ The deconvoluted peak positions correspond well with results for other similar GO based materials in the literature. ${ }^{9}$ 36, 40, 54, 61-63 As expected, the GO surface in the sp-GO (Figure 1b) has been chemically reduced during sponge formation as evidenced by the large $\mathrm{sp}^{2}$ carbon peak and lower hydroxyl, epoxide and carboxyl contents relative to the GO nanosheets. 
Table 2. Summary of deconvoluted $\mathrm{C}_{1 \mathrm{~s}}$ and $\mathrm{N}_{1 s}$ peaks in the functionalized sponge materials.

\begin{tabular}{|c|c|c|c|c|c|c|c|c|}
\hline \multirow{2}{*}{ Samples } & \multicolumn{5}{|c|}{$\mathrm{C}_{1 s}$ Peaks } & \multicolumn{3}{|c|}{$\mathrm{N}_{\mathrm{ls}}$ Peaks } \\
\hline & $\begin{array}{c}\% \mathrm{C}=\mathrm{C}\left(\mathrm{sp}^{2}\right) \\
(-284.3 \mathrm{eV})\end{array}$ & $\begin{array}{c}\% \mathrm{C}-\mathrm{C}\left(\mathrm{sp}^{3}\right) \\
(-285.6)\end{array}$ & $\begin{array}{c}\% \mathrm{C}-\mathrm{OH} \\
(-286.6)\end{array}$ & $\begin{array}{c}\% \mathrm{C}=\mathrm{O}, \mathrm{CN} \\
(-287.7)\end{array}$ & $\begin{array}{c}\% \mathrm{C}- \\
\mathrm{OOH} \\
(-289)\end{array}$ & $\begin{array}{c}\% \mathrm{HN}-\mathrm{C}=\mathrm{O} \\
(-399 \mathrm{eV})\end{array}$ & $\begin{array}{l}\text { \% C-NH2 } \\
(-400 \mathrm{eV})\end{array}$ & $\begin{array}{c}\% \mathrm{~N}-\mathrm{O}, \mathrm{NH}_{3} \\
(-401)\end{array}$ \\
\hline sp-GO & 69.7 & 14.2 & 8.6 & 3.7 & 3.7 & n.d. & n.d. & n.d. \\
\hline sp-GO/NIS & 67.9 & 17.3 & 6.4 & 5.1 & 3.3 & 68.5 & 17.8 & 13.7 \\
\hline sp-GO/LYS & 48.4 & 26.5 & 8.5 & 11.3 & 5.3 & 75.2 & 15.0 & 9.8 \\
\hline sp-GO/PLL & 59.9 & 26.1 & 3.7 & 9.5 & 0.8 & 85.3 & 9.8 & 4.8 \\
\hline
\end{tabular}

The XPS results also provide insight into the nature of bonding in the functionalized sponges. Although it is expected that the carboxyl groups present on the sp-GO surface are used in amide bond formation during the functionalization process, as shown in Figure S1b, in the sp-GO/NIS and spGO/LYS material, the percentage of carboxyl groups does not change significantly. This may be attributed to the carboxyl groups present in the NIS and LYS structures. By contrast, in the spGO/PLL sample, the percentage of carboxyl groups decreases dramatically relative to the sp-GO material. This is reasonable since PLL does not contain a large number of carboxyl groups in its structure. All functionalized samples show an increase in the $287.7 \mathrm{eV}$ carbonyl $(\mathrm{C}=\mathrm{O})$ peak. The $\mathrm{C}-$ $\mathrm{N}$ and carbonyl bonds have similar binding energy; therefore, in the functionalized sample, the increase in the 287.7 peak may be the result of carbon-nitrogen bonding in the structure. High resolution scans of the nitrogen $\mathrm{N}_{1 s}$ peak also provide information about the success of immobilization. The presence of a prominent peak at $400 \mathrm{eV}$ corresponds to the binding energy of the amine groups. The presence of this group suggests that the increase in nitrogen content is in fact derived from the antimicrobial agents and not from entrained nitrogen, or other contaminating species.

ATR-FTIR spectra were obtained for the functionalized sponge samples and used to corroborate the surface chemistry analysis performed by XPS (Figure 2). In the non-functionalized sponge samples, key peak regions were identified. A broad peak at $-3300 \mathrm{~cm}^{-1}$ is observed which corresponds to the $\mathrm{OH}$ stretching mode. This broad region may also correspond to water entrained within the sample. A large peak at $1600 \mathrm{~cm}^{-1}$ corresponds to $\mathrm{C}=\mathrm{C}$ stretching vibrations. A slight peak at $1715 \mathrm{~cm}^{-1}$ is 
attributed to the $\mathrm{C}=\mathrm{O}$ stretching vibrations in unreacted carboxyl groups. A broad peak in the range of $1300-1400 \mathrm{~cm}^{-1}$ can be assigned to $\mathrm{sp}^{3} \mathrm{CH}$ bending. In the range of $1200 \mathrm{~cm}^{-1}$ and $1110 \mathrm{~cm}^{-1}$, peaks are assigned to $\mathrm{C}-\mathrm{O}$ stretching. The peak assignments correlate well with reduced GO FTIR spectra for similar materials found in the literature, ${ }^{38-40}$ however, unlike other systems, and in line with our XPS results, the sp-GO is not completely reduced as evidenced by the presence of carboxyl, hydroxyl and carbonyl peak regions. This suggests that the sponge material has sufficient oxygen-containing groups needed for functionalization by EDC/NHS coupling chemistry.

A peak corresponding with $\mathrm{C}=\mathrm{O}$ stretching in the amide group $\mathrm{NHC}=\mathrm{O}$ is found for NIS, LYS and PLL at 1652, 1654, and $1662 \mathrm{~cm}^{-1}$ respectively (Figure 2 ) and this corresponds well with the amide I peak reported in the literature. 29,53, 64-65 This key feature found in all of the antimicrobial agents is absent in the GO and sp-GO materials and can be used to infer successful functionalization. A second amine peak in the range of $1550 \mathrm{~cm}^{-1}$ corresponds to $\mathrm{NH}$ in plane bending, and is consistent with the amide II peak in the literature. ${ }^{29}, 53,6465$ An additive effect can be observed in the functionalized samples. In both the sp-GO/NIS and sp-GO/LYS samples, the spectra of the functionalized material resemble that of sp-GO. However, after functionalization, a peak broadening occurs in the range of $1500 \mathrm{~cm}^{-1}$ and $1000 \mathrm{~cm}^{-1}$. Individual peak positions cannot be reliably identified and the spectra of the composite materials appear to be the additive result of the constituents. By contrast, in the spGO/PLL sample, while some peak broadening occurs in the range of $1000 \mathrm{~cm}^{-1}$, key features of spGO and PLL such as the $\mathrm{C}=\mathrm{O}$ stretching peak at $1700 \mathrm{~cm}^{-1}, \mathrm{C}=\mathrm{C}$ stretching at $1600 \mathrm{~cm}^{-1}$ and the amide I peak at $1650 \mathrm{~cm}^{-1}$ can still be identified. The FTIR measurements corroborate the XPS data and provide additional evidence of functionalization with the selected antimicrobial agents. 

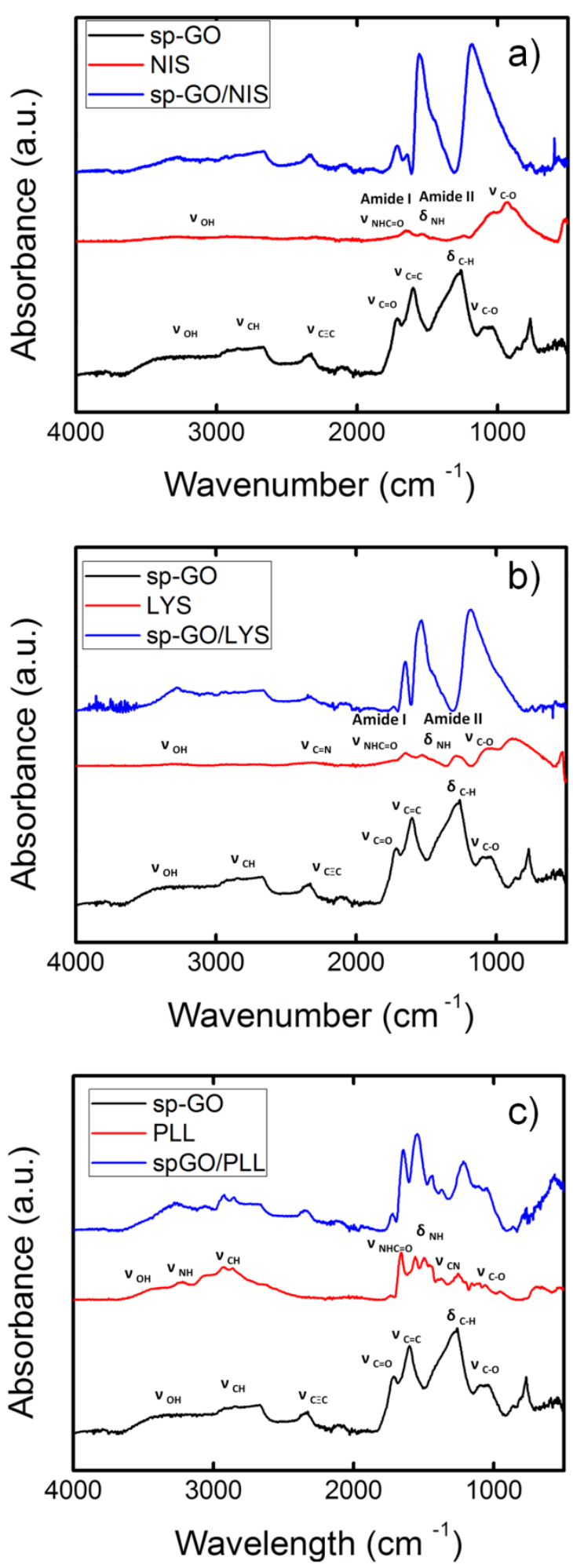

Figure 2. ATR-FTIR spectra of pristine sponges and a) sp-GO/NIS, b) sp-GO/LYS, c) sp-GO/PLL. The spectra of the antimicrobial agents alone are also shown. 


\subsection{Morphology of the GO sponges}

The pristine and functionalized sp-GO were imaged by SEM to understand the effect of functionalization on pore morphology. A hierarchical porous structure consistent with our previous work on GO sponges reduced with excessive amounts of vitamin $\mathrm{C}$ is observed in all samples. ${ }^{11}$ Hierarchical porosity is advantageous for the effective mass transport of contaminants while maintaining a high surface area for adsorption. In the pristine sp-GO sample, a two-tiered hierarchical structure is observed with large primary pore size on the order of $500 \mu \mathrm{m}$ (Figure 3a). The walls of the large primary pores are composed of smaller secondary porous structures with diameters on the order of 50-100 $\mu \mathrm{m}$ (Figure 3b). SEM images show that this hierarchical pore structure is consistent in both functionalized and pristine sponge samples (Figure 3). No apparent damage or collapse of pores is observed in the samples after functionalization suggesting that the chemical process is mild and does not damage the pore structure.

A slight expansion of the sp-GO (Figure 3a-c) pore system is observed after functionalization with the polyamide PLL (Figure 3j-1) and both the primary and secondary pores become more open and rounded. Furthermore, the pore walls in the sp-GO/PLL sample (Figure 31) appear to be thinner relative to the pristine sp-GO (Figure 3c). Exfoliation and intercalation in $\mathrm{GO} /$ polymer systems has been previously reported and was correlated to expansion of the GO stacked sheet structure and increase in inter-sheet spacing. ${ }^{66-67}$ The expansion effect and thinning of the pore walls is less pronounced in the GO/NIS (Figure 3d-f) and GO/LYS (Figure 3g-i) materials, likely due to the smaller size of the NIS and LYS biomolecules as a result of their folded structure. 

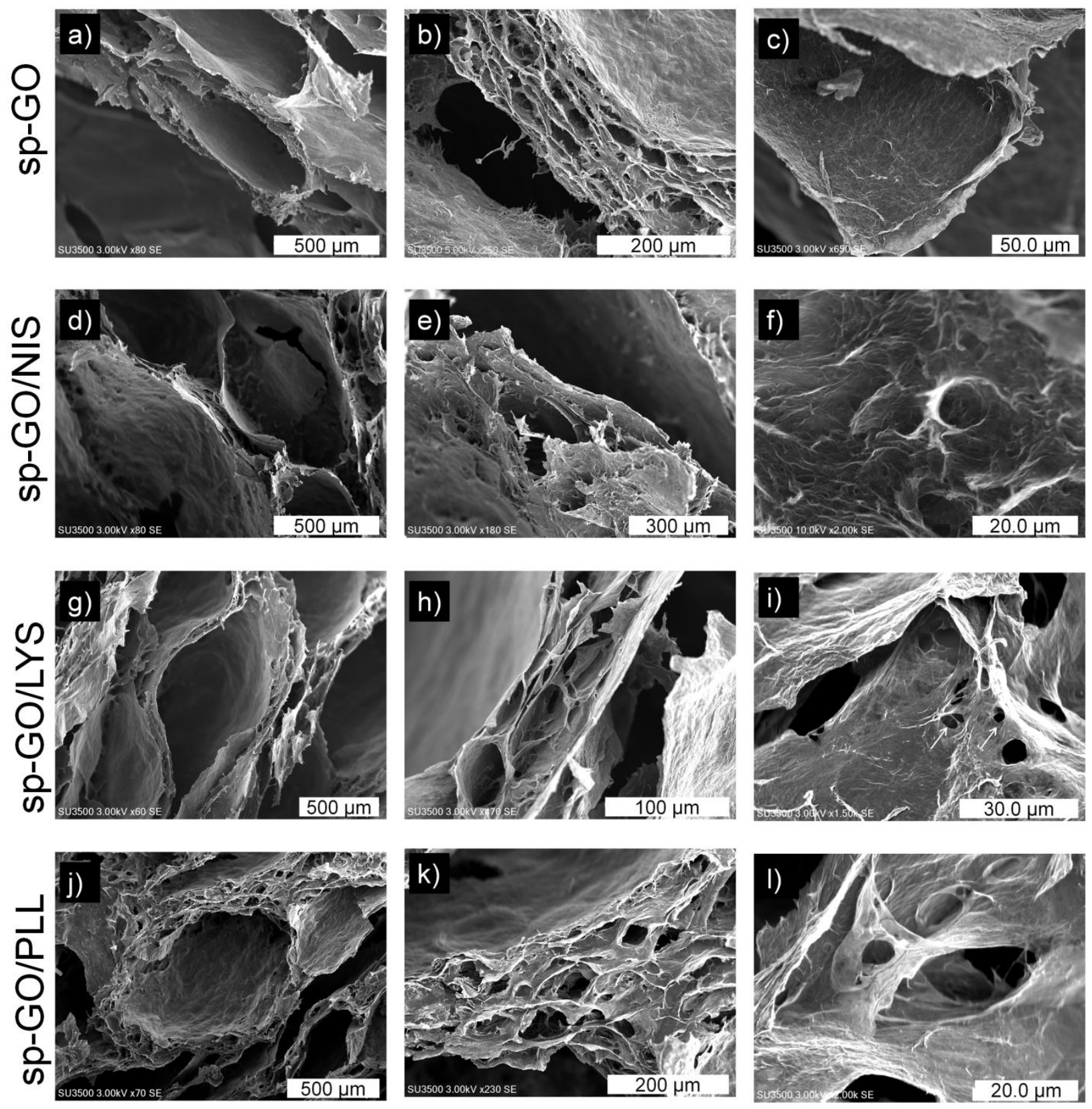

Figure 3. SEM micrographs demonstrate hierarchical porous structure in a-c) sp-GO, $d-f$ ) spGO/NIS, g-i) sp-GO/LYS, and j-l) sp-GO/PLL. 


\subsection{Antimicrobial Activity of Functionalized GO and sp-GO}

\subsubsection{Growth inhibition by functionalized nanosheets (GO/NIS, GO/LYS and GO/PLL)}

Bacterial growth curves were measured for preliminary evaluation of antimicrobial activity of NIS, LYS, and PLL before and after immobilization on the GO surface. Minimum inhibitory concentration (MIC) was determined for the selected antimicrobial agents NIS, LYS, and PLL (Table S3). All antimicrobial agents were capable of completely inhibiting growth of the model Gram-positive strain B. subtilis. However, only PLL was capable of completely inhibiting the growth of the model Gramnegative strain E. coli K12. The resistance of the Gram-negative bacterium to LYS and NIS can be explained by its outer cell structures. Lysozyme causes cleavage of bonds in peptidoglycan, the major structural component in bacterial cell walls. ${ }^{31}$ In Gram-positive organisms such as B. subtilis, the cell wall is the outermost protective layer of the cell which allows LYS to easily access its substrate. By contrast, Gram-negative organisms such as $E$. coli have an additional outer membrane surrounding the cell wall that hinders access to peptidoglycan, and allows the cells to continue to grow even in the presence of LYS, although coupling LYS with membrane destabilizing treatments can improve antimicrobial efficacy. ${ }^{68-69}$ Similarly, the outer cell membrane of Gram-negative organisms likely interferes with the mode of action of NIS. ${ }^{70}$ While NIS completely inhibited bacterial growth in the model Gram-positive organism, complete inhibition was not observed with Gram-negative E. coli at the concentrations tested, likely due to the presence of the outer membrane which prevents the antimicrobial peptide from accessing and inducing pore formation in the cytoplasmic membrane. At sub-MIC concentrations, extended lag phase and diminished growth rate were observed, as described in more detail in Figures S5-S7.

Conservation of bacteriostatic activity of the antimicrobial agents after immobilization on the GO surface was evaluated from bacterial growth curves (Figure 4). Measurement of antimicrobial behavior of suspended nanosheets poses several challenges including the color of the nanosheets themselves and the potential for nanosheet aggregation during the experiment. The nanosheets were evaluated at 250 $\mu \mathrm{g} / \mathrm{mL}$ because at this concentration the aggregation effects are minimal and do not interfere with optical density measurements (Figure S8). Although changes to bacterial growth behaviour such as 
extended lag phase and slower growth rate were observed in the presence of pristine or functionalized GO nanosheets (Figures 4, S9-S10), complete inhibition of growth was not achieved. It was not possible to increase the nanosheet concentration further due to colloidal stability limitations.

a) B. subtilis

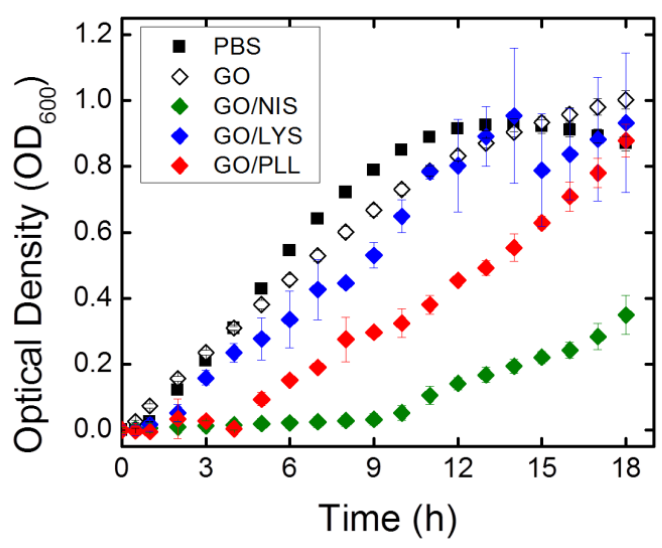

b) E. coli

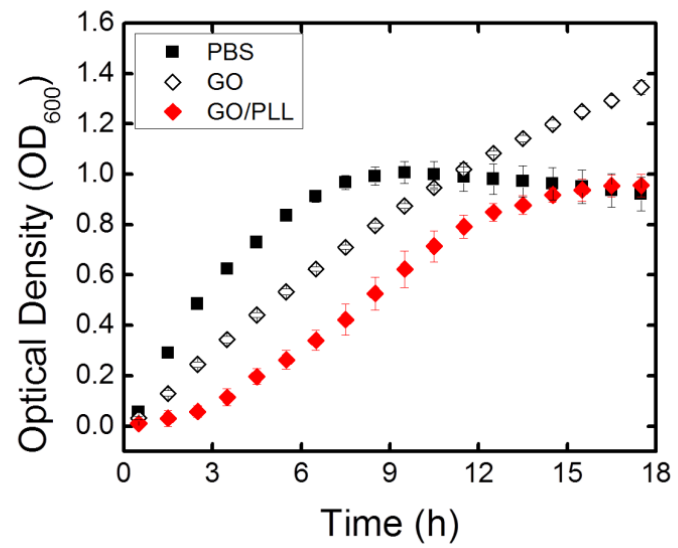

Figure 4. Representative bacterial growth curves for a) B. subtilis and b) E. coli exposed to pristine GO and functionalized GO nanosheets. Concentration of nanosheets in all conditions was $250 \mu \mathrm{g} / \mathrm{mL}$. Optical density values were normalized by subtracting the baseline optical density at the initial time point $(t=0)$. Each growth curve represents a separate biological replicate, and error bars represent \pm standard deviation on 6 technical replicates for each experiment.

Semi-quantitative analysis of the lag and exponential phases of bacterial growth (Table S4) provided insight into the impact of the functionalized nanosheets on bacterial growth dynamics. Pristine GO caused a slight decrease in growth rate but did not impact the lag phase in the organism B. subtilis. GO/LYS showed some antimicrobial activity against B. subtilis as evidenced by the slight change in growth rate. However, growth did occur at later time points. This may be an indication that the MIC was not reached or that antimicrobial efficacy was lost during incubation. ${ }^{55}$ GO/NIS showed inhibitory activity against $B$. subtilis as evidenced by an extended lag phase, significant decrease in growth rate and lower final optical density. GO/PLL led to an extended lag phase and lower growth rate, although growth occurred at later time points. Growth of E. coli was only investigated with 
pristine GO and GO/PLL because preliminary MIC experiments with NIS and LYS did not show evidence of antimicrobial activity against this Gram-negative species (Figures S5-S7). A decrease in growth rate was observed upon exposure to the functionalized GO/PLL material.

The bacteriostatic activity of the functionalized sp-GO was not evaluated by the growth inhibition assay, since optical density measurements of an opaque, solid system are not possible. More importantly, the growth inhibition assay is designed to detect planktonic phase bacteria, and due to the porous surface of the sp-GO sponge, bacterial attachment or interaction with the surface is expected which will cause error in sampling planktonic bacteria and likely result in an underestimation of total biomass in the system.

\subsubsection{Loss of membrane integrity caused by functionalized nanosheets and sponges}

The BacLight ${ }^{\ominus}$ membrane integrity assay provides information on biomass with damaged or compromised cell membranes. Although it cannot be assumed that all cells with compromised membranes are no longer viable, the membrane integrity assay nevertheless provides an indication of bactericidal activity of a material. Three-dimensional (z-stack) images were obtained by CLSM (Figure S11) and provide a qualitative representation of the bacterial membrane integrity after $15 \mathrm{hr}$ exposure to functionalized nanosheets. Cells with green fluorescence have an intact membrane, while cells with red fluorescence have damaged membranes. The model Gram-positive organism B. subtilis was evaluated against GO, GO/NIS, GO/LYS and GO/PLL nanosheets. In treatments containing the functionalized GO nanosheets, increase in red fluorescence is observed relative to the pristine GO. The model Gram-negative organism E. coli was evaluated against GO and GO/PLL nanosheets. Although there is no evidence of membrane damage in the GO/PLL condition, there is clear evidence of bacterial aggregation. In suspension, the functionalized nanosheets and bacteria are free to move. Electrostatic interactions between the negatively charged bacteria and the cationic PLL would lead to the aggregation effect observed in the CLSM images (Figure S11). In the context of water treatment, such interactions may be advantageous, as they may lead to improved removal of bacteria from the water stream. 
For each treatment, a minimum of 30 two-dimensional images were captured and analyzed by ImageJ to quantify the relative red and green fluorescence (Figure 5). The Gram-positive model organism $B$. subtilis shows statistically significant membrane damage upon exposure to GO/NIS, GO/LYS and GO/PLL in nutrient poor conditions (PBS) for $15 \mathrm{hr}$. No statistically significant increase in membrane damage was observed following exposure to pristine GO nanosheets relative to PBS alone which suggests that increase in membrane damage with the functionalized nanosheets may be attributed to the presence of the antimicrobial agents rather than intrinsic antimicrobial activity of GO.

\section{Nanosheets}
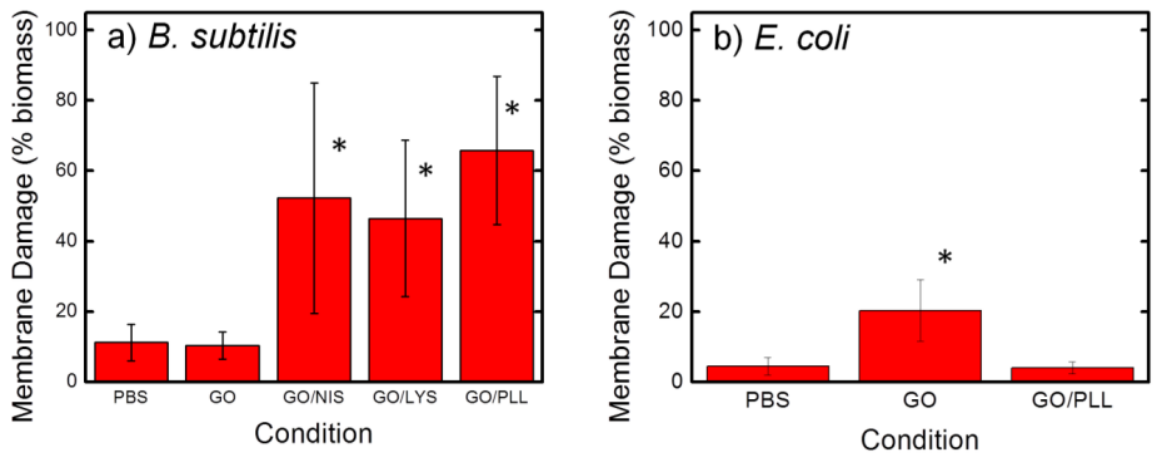

Figure 5. Membrane damage in a) B. subtilis 6633 and b) E. coli K12 exposed to functionalized nanosheets $(250 \mu \mathrm{g} / \mathrm{mL})$ for $15 \mathrm{hr}$ in PBS. Results represent three biological replicates with a minimum of 30 images analyzed for each condition. Statistical significance was evaluated by the twotailed $\mathrm{t}$-test with a significance threshold of $\mathrm{p}<0.03$.

For E. coli, no statistically significant membrane damage was observed with GO/PLL. However, a small but statistically significant increase in membrane damage was observed upon exposure to pristine GO. Evidence of antimicrobial activity of GO against E. coli and higher susceptibility of Gramnegative strains has been previously reported in the literature and are consistent with the observations in this work..$^{54}$ It has been hypothesized that the resistance of Gram-positive organisms to GO may be the result of the thicker cell wall. ${ }^{54}$ Future investigations with greater control of material properties may lend insight into this phenomenon. The lack of antimicrobial activity in the GO/PLL condition may be attributed to concentration limitations. The MIC value of PLL against E. coli was substantially higher than against $B$. subtilis and this may explain the difference in membrane damage observed in 
these inactivation experiments. Due to limitations of the experimental method (namely, aggregation at high concentration), the nanosheet concentration tested was $250 \mu \mathrm{g} / \mathrm{mL}$, and the effective PLL concentration in the GO/PLL condition was less than half of the observed E. coli MIC value (Table S3). Therefore, it is not surprising that significant cell death was not observed. Nonetheless, as previously highlighted, the qualitative observations of increased aggregation in the GO/PLL conditions suggests that the composite system may hold promise in the field of water treatment due to the potential for bacteria removal by physicochemical filtration.

Antimicrobial activity of the functionalized sponges was confirmed with the membrane integrity assay only, since as previously discussed the growth inhibition assay could not be reliably applied to this system. Representative 3D (z-stack) CLSM images of the sponge after incubation with B. subtilis and E. coli are shown in Figure 6. The sponge material partially blocks light and therefore the images capture information about cells on the sponge surface or in the sponge pore space.

\section{B. subtilis ATCC 6633}
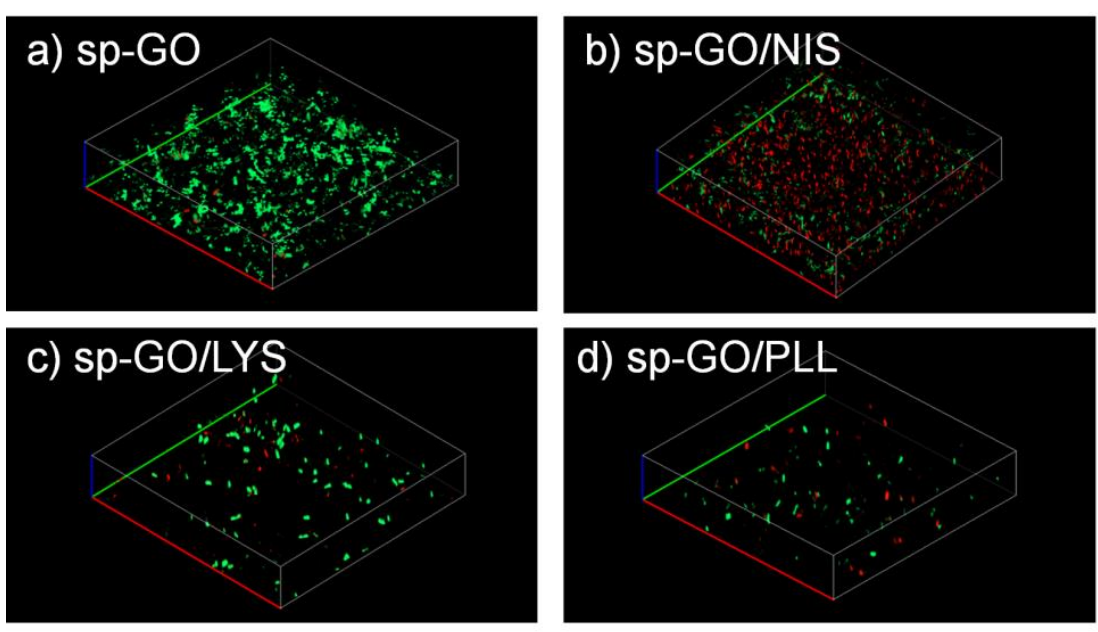

\section{E. coli K12}
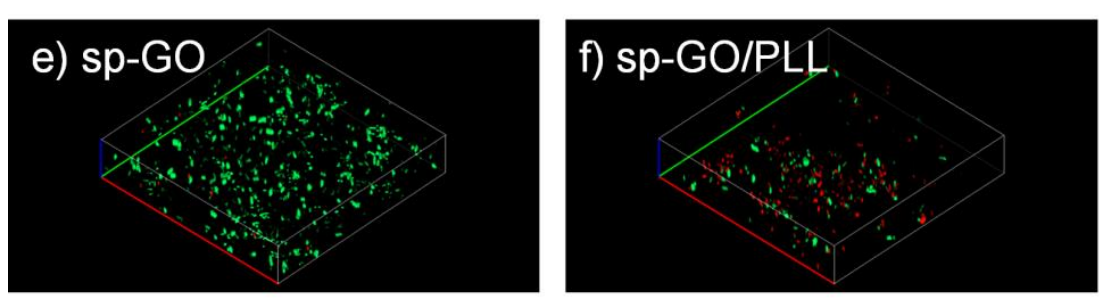

Figure 6. CLSM z-stack images of model organisms after $15 \mathrm{hr}$ incubation with sponges in nutrient poor conditions (PBS). The conditions shown are a) B. subtilis with pristine sp-GO, b) B. subtilis with 
sp-GO/NIS, c) B. subtilis with sp-GO/LYS, d) B. subtilis with sp-GO/PLL, e) E. coli with sp-GO, and f) $E$. coli with sp-GO/PLL. In all experimental conditions, $0.125 \mathrm{~g}$ of sponge and $200 \mu \mathrm{L}$ of cell suspension $\left(\mathrm{OD}_{600}=1\right)$ were incubated together. Images represent the sponge and buffer system. Scale $(\mathrm{x}, \mathrm{y}, \mathrm{z})=(100 \mu \mathrm{m}, 100 \mu \mathrm{m}, 20 \mu \mathrm{m})$.

CLSM images were analyzed using colorimetric area based methods using ImageJ as described in the methods, and results are presented in Figure 7. The Gram-positive B. subtilis experienced an increase in membrane damage when exposed to the functionalized sponges relative to the pristine sp-GO and the control (PBS alone). No statistically significant increase in membrane damage was observed in the sp-GO material relative to the PBS control. Therefore, loss of cell membrane integrity upon exposure to the functionalized sponges is attributed to the presence of the antimicrobial agents and not to antimicrobial properties of the sp-GO itself.

The Gram-negative E. coli exhibited unexpected behavior in the presence of the functionalized sponges. While a statistically significant increase in cell damage was seen in the sp-GO/PLL sample, little or no cell membrane damage was observed in the pristine sp-GO condition relative to the control (Figure 7). This observation is noteworthy, as the GO nanosheet treatment resulted in a small but statistically significant increase in membrane damage relative to the control in the same species (Figure 5). The absence of any detectable antimicrobial activity by the sp-GO material might be attributed in part to the lower oxidation state of the sp-GO. While the GO nanosheets are highly oxidized, the spGO has been partially reduced during the sponge synthesis. In the literature, a discrepancy in antimicrobial activity dependent on the oxidation state has been reported. ${ }^{19,}{ }^{22}$ Furthermore, a high density of edges has been correlated to higher antimicrobial activity of GO nanosheets. ${ }^{17-18}$ In sp-GO, the partially reduced GO sheets are immobilized, thereby limiting edge effects and decreasing membrane damage by mechanical means. ${ }^{17}$ Due to differences in their physical and chemical properties, the antimicrobial activities of GO and sp-GO cannot be compared directly to one another. However, the divergent pattern in bacterial behavior upon exposure to these different materials is noteworthy as it highlights the variability in antimicrobial properties of graphene based materials. 
Future studies aimed at developing insight into the effect of oxidation state and physical structure on antimicrobial activity could allow for the development of tunable GO-based antimicrobial systems.

\section{Sponges}
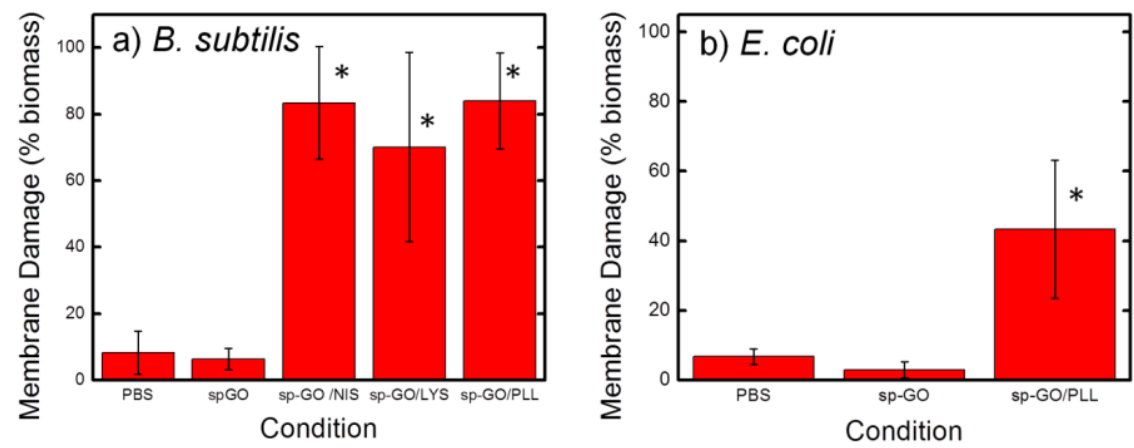

Figure 7. Membrane damage in a) B. subtilis 6633 and b) E. coli $\mathrm{K} 12$ exposed to functionalized sponges for $15 \mathrm{hr}$ in PBS buffer. Results represent three biological replicates with a minimum of 30 images analyzed for each condition. Statistical significance was evaluated by the two-tailed t-test with a significance threshold of $\mathrm{p}<0.03$.

\subsection{Material Performance in Continuous Flow System}

Removal rates of bacteria by the novel filtration medium were evaluated in a continuous flow column system. While the removal rates of various chemical contaminants using graphene based systems have been evaluated in batch mode, ${ }^{4}$ this configuration is less suitable to evaluate the removal of bacteria due to complex phenomena such as agglomeration, chain-forming behavior, biofilm development, and bacterial swim capability. Gravity filtration experiments have been used to study the removal of bacteria by graphene based nanocomposites ${ }^{47,}{ }^{49}$ or networks, ${ }^{24,50}$ however, bacterial removal by graphene based macrostructures in a continuous flow mode has not been previously evaluated. A continuous flow system (packed column) as shown in Figure S12 was used to study removal of $B$. subtilis and E. coli with sp-GO or sp-GO/PLL as filter media. In these proof-of-concept experiments, only the sp-GO/PLL was tested as a functionalized material as it exhibited promising antimicrobial activity against both strains of bacteria (Figure 7).

Representative bacteria breakthrough curves are shown in Figure 8. Retention of bacteria by the filter material was determined by numerical integration of the breakthrough curves to compare the performance of the functionalized sp-GO/PLL material to the pristine sp-GO. The overall retention 
of B. subtilis by sp-GO was $45 \%$, while retention by sp-GO/PLL was $59 \%$. The mechanism of removal is likely by a combination of physicochemical attachment and physical straining. ${ }^{71}$ The physical properties of the sp-GO and sp-GO/PLL were equivalent and therefore the contribution of physical straining to bacterial removal is expected to be similar in both materials. Hence, the improved bacteria retention by sp-GO/PLL is likely the result of electrostatic interactions, due to the cationic polyamide PLL. The breakthrough profile for the sp-GO/PLL condition shows a deflection point after $60 \mathrm{~min}$ revealing improved bacteria retention in the first $120 \mathrm{~min}$ of operation (Figure 8a). Culturability of bacteria in the effluent also decreased in the sp-GO/PLL condition relative to sp-GO (Figure 8a). A slight difference in transport behavior is also observed in the flushing phase of the experiment. After 180 min of injection, the bacterial suspension was replaced with PBS. While the concentration of bacteria in the effluent began to drop immediately, in the sp-GO column, the concentration never reached background levels suggesting that the retained bacteria was only weakly bound to the sponge and was being continuously released from the filter media. By contrast, in the sp-GO/PLL column, the effluent concentration reached background levels more rapidly suggesting that bacteria were more tightly bound to the filter medium and less likely to contaminate the filtered effluent. The kinetic measurements in this experimental set-up shed light on transport phenomena that may not be noted in batch or gravity filtration experiments. 


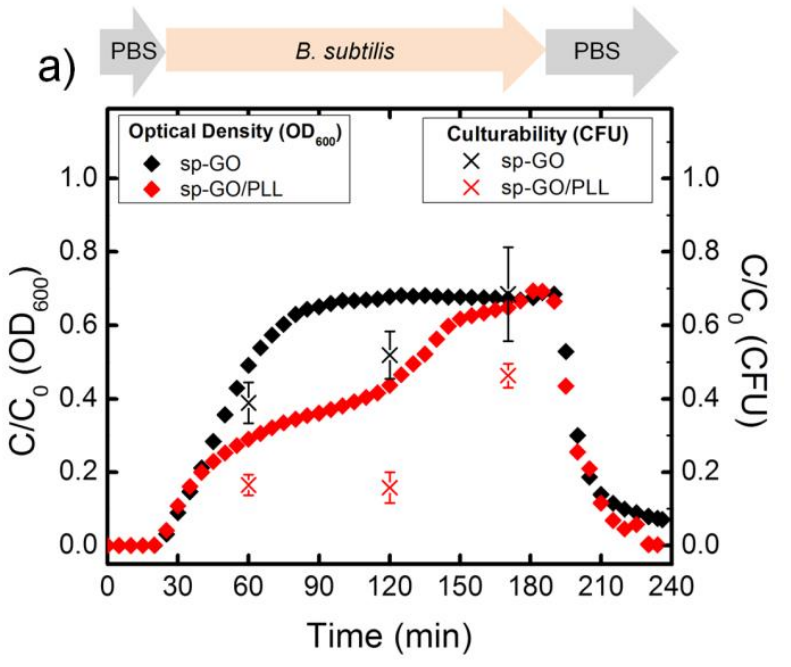

c) B. subtilis, sp-GO

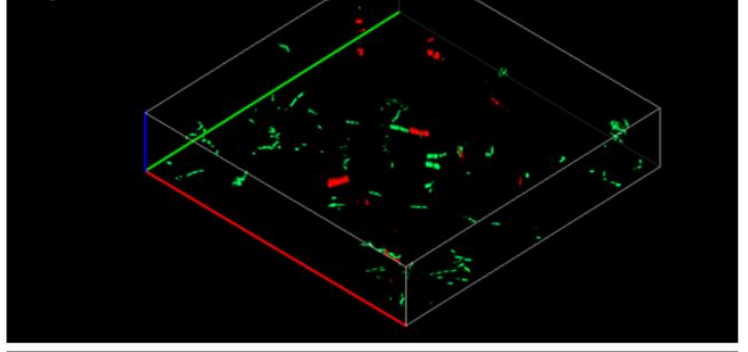

d) B. subtilis, sp-GO/PLL

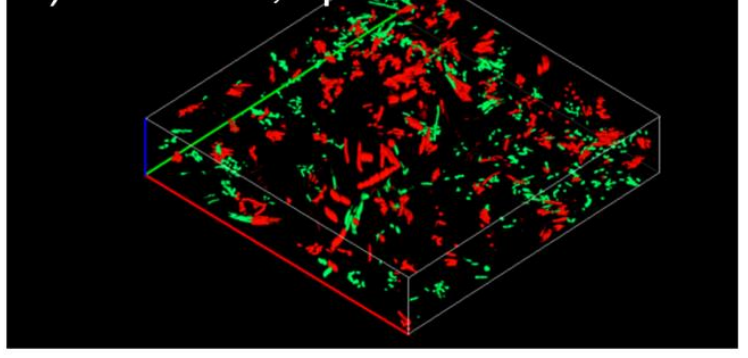

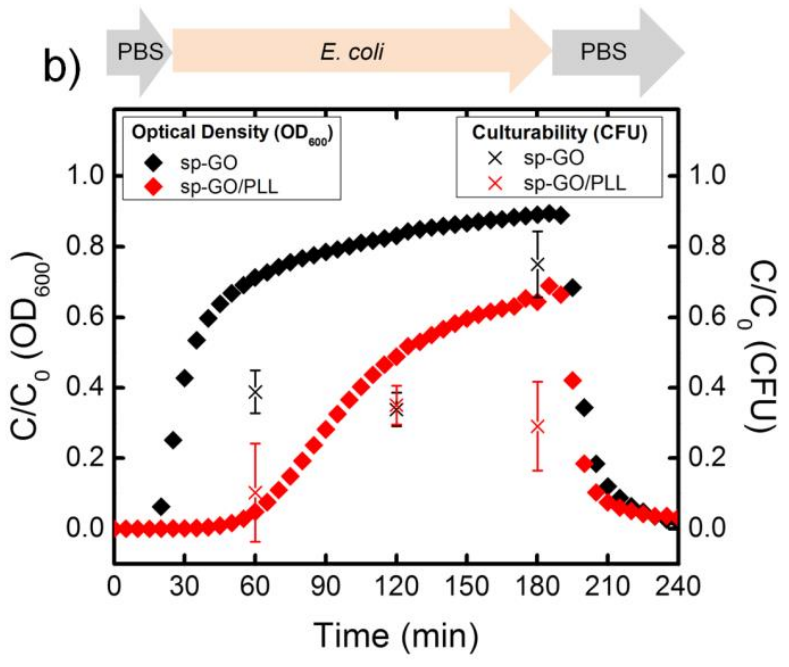
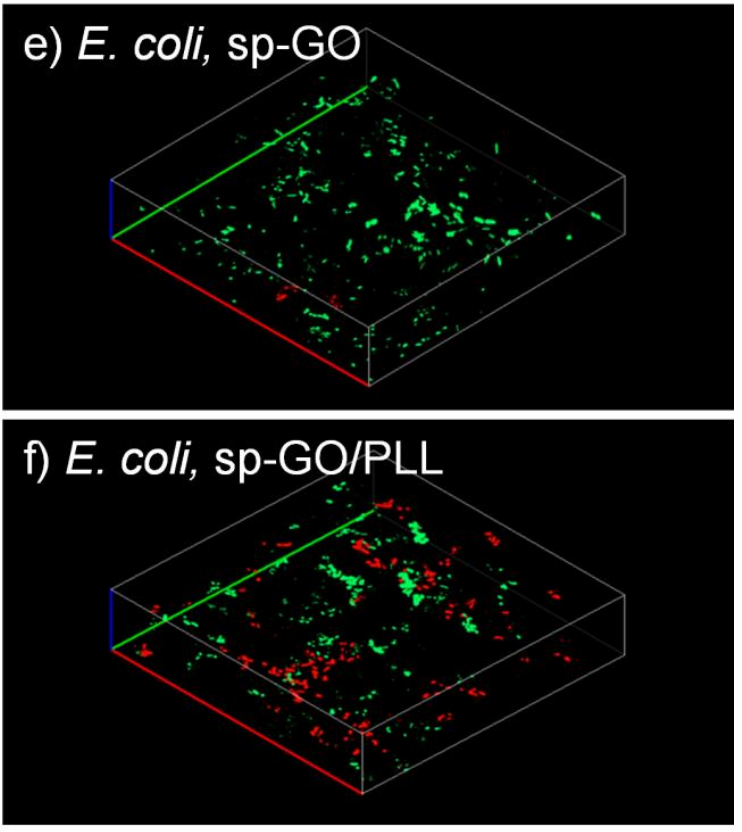

Figure 8. Representative breakthrough curves of a) B. subtilis 6633 and b) E. coli $\mathrm{K} 12\left(\mathrm{OD}_{600}=0.5\right)$ filtered through the sp-GO and sp-GO/PLL material. Bacteria concentration in the effluent was recorded by optical density measurements and colony counting (CFU) and is normalized to influent concentration. Representative CLSM z-stack images of c) B. subtilis in sp-GO filter, d) B. subtilis in sp-GO/PLL filter, e) $E$. coli in sp-GO filter, and f) $E$. coli in sp-GO/PLL filter after $180 \mathrm{~min}$ use in column are also provided. Scale $(\mathrm{x}, \mathrm{y}, \mathrm{z})=(100 \mu \mathrm{m}, 100 \mu \mathrm{m}, 20 \mu \mathrm{m})$.

Similarly, an increase in E. coli retention, as measured by optical density and culturability, was observed in the functionalized sp-GO/PLL relative to the sp-GO control (Figure 8b). The retention of E. coli by sp-GO was $25 \%$, while retention by sp-GO/PLL was $61 \%$. In the column packed with the pristine 
sp-GO, the retention of $E$. coli was lower than the retention of B. subtilis. This discrepancy may be related to the chain-forming behavior of $B$. subtilis which allows for physical straining to play a more significant role in bacteria retention. Modulating the pore size and structure, packing density and flow parameters may improve filtration of a broader range of bacteria by increasing retention by both physicochemical filtration and physical straining.

The antimicrobial activity of the filter media in continuous flow mode was evaluated. Samples of the spent column were obtained immediately after 180 min operation, stained and imaged by CLSM (Figure $8 \mathrm{c}-\mathrm{f}$ ). The percentage of $B$. subtilis cells with membrane damage was $5 \pm 2 \%$ in sp-GO and 53 $\pm 10 \%$ in sp-GO/PLL. These results suggest that an antimicrobial effect is observed in a flow mode as well in batch operation (Figure 7). It is important to note however, that the membrane damage was slightly higher in the batch system than in the column system. This discrepancy may be attributed to longer exposure time to the antimicrobial agents in the batch configuration. E. coli membrane damage was $2 \pm 2 \%$ in sp-GO and $31 \pm 6 \%$ in sp-GO/PLL. The increase in cell membrane damage in both model organisms upon exposure to the functionalized sp-GO/PLL material demonstrates that antimicrobial activity does not require extremely long contact time and antimicrobial properties are retained in a flow system.

\section{Conclusions}

Biologically-derived antimicrobial agents hold promise in antimicrobial device applications due to their capacity for immobilization, relatively low cost, and safety. In this work, growth inhibition assays showed that while the antimicrobial agents show promise, they are not all effective against the classes of bacteria tested. Namely, NIS and LYS are only effective against the Gram-positive model organism B. subtilis, while PLL inhibited the growth of both B. subtilis and Gram-negative E. coli. The GO nanosheet building blocks were functionalized by the natural, antimicrobial agents using carbodiimide (EDC/NHS) coupling chemistry and antimicrobial activity of GO nanosheets was improved with the incorporation of the natural antimicrobial agents. The direct utilization of antimicrobial GO 
nanosheets for water treatment presents challenges, due to difficulty in removing the nanomaterial from the treated water. Therefore, the hierarchical sp-GO $\mathrm{GO}^{11}$ sponge designed for water treatment applications was functionalized using the coupling methods developed in the colloidal GO system. Functionalization of the surface was confirmed by XPS and FTIR spectroscopy. The sp-GO material has a hierarchical pore structure, and the pore architecture is not altered after functionalization, as shown by SEM. Antimicrobial activity of the functionalized sponge was evaluated by membrane integrity assay, both in batch and continuous flow (column) systems. Increase in membrane damage upon exposure to the functionalized material was observed relative to PBS alone and pristine nonfunctionalized sp-GO, although complete loss of viability was not achieved.

In order to gain insight into the applicability of the sp-GO as a filtration medium, packed-column bacterial transport experiments were performed. Bacteria retention was improved in the functionalized sp-GO/PLL material relative to the pristine sp-GO. The improved retention of bacteria by the functionalized material is likely due to electrostatic interactions, since the physical characteristics of the filter media were equivalent. The retention of the two model bacteria varied, and it is likely that the chain forming behavior of B. subtilis contributed to additional bacterial retention by physical straining. In order to further improve bacteria retention and to develop an effective filtration system, the packing density and pore size of the sponge material could be tuned to increase the contribution of straining phenomena to bacteria retention. Characterization of spent samples of the sponge material after use in the continuous flow system showed up to $-50 \%$ membrane damage. The novel, functionalized, hierarchical, antimicrobial sponge exhibits improved bacteria retention in continuous flow filtration and has demonstrated antimicrobial activity in both batch and continuous flow tests.

\section{Supporting Information}

Schematic of functionalization of GO nanosheets and sp-GO sponges, Zeta-potential measurements of functionalized GO nanosheets, XPS measurements of functionalized nanosheets and sponges, Deconvoluted $\mathrm{C}_{1 \mathrm{~s}}$ and $\mathrm{N}_{1 \mathrm{~s}}$ peaks of functionalized nanosheets and sponges, ATR-FTIR spectra of functionalized nanosheets, MIC experiments with free antimicrobial agents, Growth inhibition experiments with functionalized nanosheets, CLSM images of functionalized nanosheets. 


\section{Notes}

The authors declare no competing financial interest.

\section{Acknowledgments}

The authors acknowledge the Canada Research Chairs Program, the Natural Sciences and Engineering Research Council of Canada (NSERC), the Canada Foundation for Innovation, the NSERCCREATE program and McGill University for the MEUSMA award. AF was supported by the NSERC-CREATE program and the MEUSMA award. NY was supported by McGill Engineering Doctoral Award (MEDA) and a Eugenie Ulmer-Lamothe award. MO was supported by a NSERC

Postdoctoral Fellowship. We are grateful to the Advanced Bioimaging Facility at McGill University for making the Zeiss 800 confocal laser scanning microscope available to us. 


\section{References}

(1) Andrade, L.; O'Dwyer, J.; O'Neill, E.; Hynds, P. Surface Water Flooding, Groundwater Contamination, and Enteric Disease in Developed Countries: A Scoping Review of Connections and Consequences. Environ. Pollut. 2018, 236, 540-549, DOI: 10.1016/j.envpol.2018.01.104.

(2) Cann, K. F.; Thomas, D. R.; Salmon, R. L.; Wyn-Jones, A. P.; Kay, D. Extreme Water-Related Weather Events and Waterborne Disease. Epidemiol. Infect. 2013, 141 (4), 671-686, DOI: $10.1017 /$ S0950268812001653.

(3) Perreault, F.; Fonseca De Faria, A.; Elimelech, M. Environmental Applications of Graphene-Based Nanomaterials. Chem. Soc. Rev. 2015, 44 (16), 5861-5896, DOI: 10.1039/c5cs00021a.

(4) Shen, Y.; Fang, Q.; Chen, B. Environmental Applications of Three-Dimensional Graphene-Based Macrostructures: Adsorption, Transformation, and Detection. Environ. Sci. Technol. 2015, 49 (1), 67-84, DOI: $10.1021 /$ es504421y.

(5) Chen, Y.; Chen, L.; Bai, H.; Li, L. Graphene Oxide-Chitosan Composite Hydrogels as BroadSpectrum Adsorbents for Water Purification. J. Mater. Chem. A 2013, 1 (6), 1992-2001, DOI: 10.1039/c2ta00406b.

(6) Fang, Q.; Shen, Y.; Chen, B. Synthesis, Decoration and Properties of Three-Dimensional Graphene-Based Macrostructures: A Review. Chem. Eng. J. 2015, 264, 753-771, DOI: 10.1016/j.cej.2014.12.001.

(7) Luan, V. H.; Chung, J. S.; Kim, E. J.; Hur, S. H. The Molecular Level Control of ThreeDimensional Graphene Oxide Hydrogel Structure by Using Various Diamines. Chem. Eng. J. 2014, 246, 64-70, DOI: 10.1016/j.cej.2014.01.105.

(8) Xu, Y.; Wu, Q.; Sun, Y.; Bai, H.; Shi, G. Three-Dimensional Self-Assembly of Graphene Oxide and DNA Into Multifunctional Hydrogels. ACS Nano 2010, 4 (12), 7358-7362, DOI: $10.1021 / \mathrm{nn} 1027104$.

(9) Zhang, X.; Sui, Z.; Xu, B.; Yue, S.; Luo, Y.; Zhan, W.; Liu, B. Mechanically Strong and Highly Conductive Graphene Aerogel and its Use as Electrodes for Electrochemical Power Sources. J. Mater. Chem. 2011, 21 (18), 6494-6497, DOI: 10.1039/c1jm10239g.

(10) Yousefi, N.; Lu, X.; Elimelech, M.; Tufenkji, N. Environmental Performance of Graphene-Based 3D Macrostructures. Nat. Nanotechnol. 2019, DOI: 10.1038/s41565-018-0325-6.

(11) Yousefi, N.; Wong, K. K. W.; Hosseinidoust, Z.; Sørensen, H. O.; Bruns, S.; Zheng, Y.; Tufenkji, N. Hierarchically Porous, Ultra-Strong Reduced Graphene Oxide-Cellulose Nanocrystal Sponges for Exceptional Adsorption of Water Contaminants. Nanoscale 2018, 10 (15), 7171-7184, DOI: $10.1039 / \mathrm{c} 7 \mathrm{nr} 09037 \mathrm{~d}$.

(12) Rao, R.; Pint, C. L.; Islam, A. E.; Weatherup, R. S.; Hofmann, S.; Meshot, E. R.; Wu, F.; Zhou, C.; Dee, N.; Amama, P. B.; Carpena-Nuñez, J.; Shi, W.; Plata, D. L.; Penev, E. S.; Yakobson, B. I.; 
Balbuena, P. B.; Bichara, C.; Futaba, D. N.; Noda, S.; Shin, H.; Kim, K. S.; Simard, B.; Mirri, F.; Pasquali, M.; Fornasiero, F.; Kauppinen, E. I.; Arnold, M.; Cola, B. A.; Nikolaev, P.; Arepalli, S.; Cheng, H. M.; Zakharov, D. N.; Stach, E. A.; Zhang, J.; Wei, F.; Terrones, M.; Geohegan, D. B.; Maruyama, B.; Maruyama, S.; Li, Y.; Adams, W. W.; Hart, A. J. Carbon Nanotubes and Related Nanomaterials: Critical Advances and Challenges for Synthesis toward Mainstream Commercial Applications. ACS Nano 2018, 12 (12), 11756-11784, DOI: 10.1021/acsnano.8b06511.

(13) Yang, W.; Wang, C. Graphene and the Related Conductive Inks for Flexible Electronics. J. Mater. Chem. C 2016, 4 (30), 7193-7207, DOI: 10.1039/c6tc01625a.

(14) Akhavan, O.; Ghaderi, E. Toxicity of Graphene and Graphene Oxide Nanowalls Against Bacteria. ACS Nano 2010, 4 (10), 5731-5736, DOI: 10.1021/nn101390x.

(15) Gurunathan, S.; Han, J. W.; Abdal Dayem, A.; Eppakayala, V.; Kim, J. H. Oxidative StressMediated Antibacterial Activity of Graphene Oxide and Reduced Graphene Oxide in Pseudomonas aeruginosa. Int. J. Nanomed. 2012, 7, 5901-5914, DOI: 10.2147/IJN.S37397.

(16) Perreault, F.; De Faria, A. F.; Nejati, S.; Elimelech, M. Antimicrobial Properties of Graphene Oxide Nanosheets: Why Size Matters. ACS Nano 2015, 9 (7), 7226-7236, DOI: 10.1021/acsnano.5b02067.

(17) Lin, N.; Berton, P.; Moraes, C.; Rogers, R. D.; Tufenkji, N. Nanodarts, Nanoblades, and Nanospikes: Mechano-Bactericidal Nanostructures and Where to Find Them. Adv. Colloid Interface Sci. 2018, 252, 55-68, DOI: 10.1016/j.cis.2017.12.007.

(18) Liu, S.; Hu, M.; Zeng, T. H.; Wu, R.; Jiang, R.; Wei, J.; Wang, L.; Kong, J.; Chen, Y. Lateral Dimension-Dependent Antibacterial Activity of Graphene Oxide Sheets. Langmuir 2012, 28 (33), 12364-12372, DOI: 10.1021/la3023908.

(19) Liu, S.; Zeng, T. H.; Hofmann, M.; Burcombe, E.; Wei, J.; Jiang, R.; Kong, J.; Chen, Y. Antibacterial Activity of Graphite, Graphite oxide, Graphene Oxide, and Reduced Graphene Oxide: Membrane and Oxidative Stress. ACS Nano 2011, 5 (9), 6971-6980, DOI: 10.1021/nn202451x.

(20) Lu, X.; Feng, X.; Werber, J. R.; Chu, C.; Zucker, I.; Kim, J. H.; Osuji, C. O.; Elimelech, M. Enhanced Antibacterial Activity Through the Controlled Alignment of Graphene Oxide Nanosheets. Proc. Natl. Acad. Sci. U. S. A. 2017, 114 (46), E9793-E9801, DOI: 10.1073/pnas.1710996114.

(21) Hegab, H. M.; Elmekawy, A.; Zou, L.; Mulcahy, D.; Saint, C. P.; Ginic-Markovic, M. The Controversial Antibacterial Activity of Graphene-Based Materials. Carbon 2016, 105, 362-376, DOI: 10.1016/j.carbon.2016.04.046.

(22) Szunerits, S.; Boukherroub, R. Antibacterial Activity of Graphene-Based Materials. J. Mater. Chem. B 2016, 4 (43), 6892-6912, DOI: 10.1039/c6tb01647b.

(23) Musico, Y. L. F.; Santos, C. M.; Dalida, M. L. P.; Rodrigues, D. F. Surface Modification of Membrane Filters Using Graphene and Graphene Oxide-Based Nanomaterials for Bacterial 
Inactivation and Removal. ACS Sustainable Chem. Eng. 2014, 2 (7), 1559-1565, DOI: $10.1021 / \mathrm{sc} 500044 \mathrm{p}$.

(24) Zeng, X.; Wang, G.; Liu, Y.; Zhang, X. Graphene-Based Antimicrobial Nanomaterials: Rational Design and Applications for Water Disinfection and Microbial Control. Environ. Sci.: Nano 2017, 4 (12), 2248-2266, DOI: 10.1039/c7en00583k.

(25) Deng, C. H.; Gong, J. L.; Zhang, P.; Zeng, G. M.; Song, B.; Liu, H. Y. Preparation of Melamine Sponge Decorated with Silver Nanoparticles-Modified Graphene for Water Disinfection. J. Colloid Interface Sci. 2017, 488, 26-38, DOI: 10.1016/j.jcis.2016.10.078.

(26) Zeng, X.; McCarthy, D. T.; Deletic, A.; Zhang, X. Silver/Reduced Graphene Oxide Hydrogel as Novel Bactericidal Filter for Point-of-Use Water Disinfection. Adv. Funct. Mater. 2015, 25 (27), 4344-4351, DOI: 10.1002/adfm.201501454.

(27) Wang, X.; Liu, Z.; Ye, X.; Hu, K.; Zhong, H.; Yuan, X.; Xiong, H.; Guo, Z. A Facile One-Pot Method to Two Kinds of Graphene Oxide-Based Hydrogels with Broad-Spectrum Antimicrobial Properties. Chem. Eng. J. 2015, 260, 331-337, DOI: 10.1016/j.cej.2014.08.102.

(28) Cole, M. A.; Scott, T. F.; Mello, C. M. Bactericidal Hydrogels via Surface Functionalization with Cecropin A. ACS Biomater. Sci. Eng. 2016, 2 (11), 1894-1904, DOI: 10.1021/acsbiomaterials.6b00266.

(29) Kanchanapally, R.; Nellore, B. P. V.; Sinha, S. S.; Pedraza, F.; Jones, S. J.; Pramanik, A.; Chavva, S. R.; Tchounwou, C.; Shi, Y.; Vangara, A.; Sardar, D.; Ray, P. C. Antimicrobial Peptide-Conjugated Graphene Oxide Membrane for Efficient Removal and Effective Killing of Multiple Drug Resistant Bacteria. RSC Adv. 2015, 5 (24), 18881-18887, DOI: 10.1039/c5ra01321f.

(30) Viraka Nellore, B. P.; Kanchanapally, R.; Pedraza, F.; Sinha, S. S.; Pramanik, A.; Hamme, A. T.; Arslan, Z.; Sardar, D.; Ray, P. C. Bio-Conjugated CNT-Bridged 3D Porous Graphene Oxide Membrane for Highly Efficient Disinfection of Pathogenic Bacteria and Removal of Toxic Metals from Water. ACS Appl. Mater. Interfaces 2015, 7(34), 19210-19218, DOI: 10.1021/acsami.5b05012.

(31) Thallinger, B.; Prasetyo, E. N.; Nyanhongo, G. S.; Guebitz, G. M. Antimicrobial Enzymes: An Emerging Strategy to Fight Microbes and Microbial Biofilms. Biotechnol. J. 2013, 8 (1), 97-109, DOI: 10.1002/biot.201200313.

(32) Duan, L.; Wang, Y.; Zhang, Y.; Liu, J. Graphene Immobilized Enzyme/Polyethersulfone Mixed Matrix Membrane: Enhanced Antibacterial, Permeable and Mechanical Properties. Appl. Surf. Sci. 2015, 355, 436-445, DOI: 10.1016/j.apsusc.2015.07.127.

(33) Eby, D. M.; Luckarift, H. R.; Johnson, G. R. Hybrid Antimicrobial Enzyme and Silver Nanoparticle Coatings for Medical Instruments. ACS Appl. Mater. Interfaces 2009, 1 (7), 1553-1560, DOI: 10.1021/am9002155. 
(34) Xu, L. Q.; Zhang, B.; Chen, Y.; Neoh, K. G.; Kang, E. T.; Fu, G. D. Reactive Graphene Oxide Nanosheets: A Versatile Platform for the Fabrication of Graphene Oxide-Biomolecule/Polymer Nanohybrids. Macromol. Rapid Commun. 2013, 34 (3), 234-238, DOI: 10.1002/marc.201200635.

(35) Zhang, J.; Zhang, J.; Zhang, F.; Yang, H.; Huang, X.; Liu, H.; Guo, S. Graphene Oxide as a Matrix for Enzyme Immobilization. Langmuir 2010, 26 (9), 6083-6085, DOI: 10.1021/la904014z.

(36) Santos, M. R. E.; Fonseca, A. C.; Mendonça, P. V.; Branco, R.; Serra, A. C.; Morais, P. V.; Coelho, J. F. J. Recent Developments in Antimicrobial Polymers: A Review. Materials 2016, 9 (7), DOI: $10.3390 /$ MA9070599.

(37) Shima, S.; Matsuoka, H.; Iwamoto, T.; Sakai, H. Antimicrobial Action of $\varepsilon$-Poly-L-Lysine. J. Antibiot. 1984, 37 (11), 1449-1455, DOI: 10.7164/antibiotics.37.1449.

(38) Ouyang, Y.; Cai, X.; Shi, Q.; Liu, L.; Wan, D.; Tan, S.; Ouyang, Y. Poly-l-Lysine-Modified Reduced Graphene Oxide Stabilizes the Copper Nanoparticles with Higher Water-Solubility and Long-Term Additively Antibacterial Activity. Colloids Surf., B 2013, 107, 107-114, DOI: 10.1016/j.colsurfb.2013.01.073.

(39) Shan, C.; Yang, H.; Han, D.; Zhang, Q.; Ivaska, A.; Niu, L. Water-Soluble Graphene Covalently Functionalized by Biocompatible Poly-L-Lysine. Langmuir 2009, 25 (20), 12030-12033, DOI: 10.1021/la903265p.

(40) Some, S.; Ho, S. M.; Dua, P.; Hwang, E.; Shin, Y. H.; Yoo, H.; Kang, J. S.; Lee, D. K.; Lee, H. Dual Functions of Highly Potent Graphene Derivative-Poly-l-Lysine Composites to Inhibit Bacteria and Support Human Cells. ACS Nano 2012, 6 (8), 7151-7161, DOI: 10.1021/nn302215y.

(41) Wang, J.; Zhao, Y.; Ma, F. X.; Wang, K.; Wang, F. B.; Xia, X. H. Synthesis of a Hydrophilic Poly-l-Lysine/Graphene Hybrid Through Multiple Non-Covalent Interactions for Biosensors. J. Mater. Chem. B 2013, 1 (10), 1406-1413, DOI: 10.1039/c2tb00454b.

(42) Gálvez, A.; Abriouel, H.; López, R. L.; Omar, N. B. Bacteriocin-Based Strategies for Food Biopreservation. Int. J. Food Microbiol. 2007, 120 (1-2), 51-70, DOI: 10.1016/j.ijfoodmicro.2007.06.001.

(43) Proctor, V. A.; Cunningham, F. E. The Chemistry of Lysozyme and Its Use as a Food Preservative and a Pharmaceutical. Crit. Rev. Food Sci. Nutr. 1988, 26 (4), 359-395, DOI: 10.1080/10408398809527473.

(44) Tavakolian, M.; Okshevsky, M.; Van De Ven, T. G. M.; Tufenkji, N. Developing Antibacterial Nanocrystalline Cellulose Using Natural Antibacterial Agents. ACS Appl. Mater. Interfaces 2018, 10 (40), 33827-33838, DOI: 10.1021/acsami.8b08770.

(45) Asadishad, B.; Olsson, A. L. J.; Dusane, D. H.; Ghoshal, S.; Tufenkji, N. Transport, Motility, Biofilm Forming Potential and Survival of Bacillus subtilis Exposed to Cold Temperature and FreezeThaw. Water Res. 2014, 58, 239-247, DOI: 10.1016/j.watres.2014.03.048. 
(46) Ding, Z.; Hu, X.; Morales, V. L.; Gao, B. Filtration and Transport of Heavy Metals in Graphene Oxide Enabled Sand Columns. Chem. Eng. J. 2014, 257, 248-252, DOI: 10.1016/j.cej.2014.07.034.

(47) Hussein, M. A.; El-Shishtawy, R. M.; Alamry, K. A.; Asiri, A. M.; Mohamed, S. A. Efficient Water Disinfection Using Hybrid Polyaniline/Graphene/Carbon Nanotube Nanocomposites. Environ. Technol. 2018, 1-12, DOI: 10.1080/09593330.2018.1466921.

(48) Ngwenya, B. T.; Curry, P.; Kapetas, L. Transport and Viability of Escherichia coli Cells in Clean and Iron Oxide Coated Sand Following Coating with Silver Nanoparticles. J. Contam. Hydrol. 2015, 179, 35-46, DOI: 10.1016/j.jconhyd.2015.05.005.

(49) Ruiz, O. N.; Brown, N. A.; Shiral Fernando, K. A.; Harruff-Miller, B. A.; Gunasekera, T. S.; Bunker, C. E. Graphene Oxide-Based Nanofilters Efficiently Remove Bacteria From Fuel. Int. Biodeterior. Biodegrad. 2015, 97, 168-178, DOI: 10.1016/j.ibiod.2014.10.008.

(50) Wang, Y.; Zhang, P.; Liu, C. F.; Huang, C. Z. A Facile and Green Method to Fabricate Graphene-Based Multifunctional Hydrogels for Miniature-Scale Water Purification. RSC Adv. 2013, 3 (24), 9240-9246, DOI: 10.1039/c3ra22687e.

(51) Yousefi, N.; Lin, X.; Zheng, Q.; Shen, X.; Pothnis, J. R.; Jia, J.; Zussman, E.; Kim, J. K. Simultaneous In Situ Reduction, Self-Alignment and Covalent Bonding in Graphene Oxide/Epoxy Composites. Carbon 2013, 59, 406-417, DOI: 10.1016/j.carbon.2013.03.034.

(52) Zheng, Q.; Ip, W. H.; Lin, X.; Yousefi, N.; Yeung, K. K.; Li, Z.; Kim, J. K. Transparent Conductive Films Consisting of Ultralarge Graphene Sheets Produced by Langmuir-Blodgett Assembly. ACS Nano 2011, 5 (7), 6039-6051, DOI: 10.1021/nn2018683.

(53) Bai, Y.; Ming, Z.; Cao, Y.; Feng, S.; Yang, H.; Chen, L.; Yang, S. T. Influence of Graphene Oxide and Reduced Graphene Oxide on the Activity and Conformation of Lysozyme. Colloids Surf., B 2017, 154, 96-103, DOI: 10.1016/j.colsurfb.2017.03.011.

(54) Karahan, H. E.; Wei, L.; Goh, K.; Liu, Z.; Birer, Ö.; Dehghani, F.; Xu, C.; Wei, J.; Chen, Y. Bacterial Physiology is a Key Modulator of the Antibacterial Activity of Graphene Oxide. Nanoscale 2016, 8 (39), 17181-17189, DOI: 10.1039/c6nr05745d.

(55) Theophel, K.; Schacht, V. J.; Schlüter, M.; Schnell, S.; Stingu, C. S.; Schaumann, R.; Bunge, M. The Importance of Growth Kinetic Analysis in Determining Bacterial Susceptibility Against Antibiotics and Silver Nanoparticles. Front. Microbiol. 2014, 5 (NOV), DOI: 10.3389/fmicb.2014.00544.

(56) Hall, B. G.; Acar, H.; Nandipati, A.; Barlow, M. Growth Rates Made Easy. Mol. Biol. Evol. 2014, 31 (1), 232-238, DOI: $10.1093 / \mathrm{molbev} / \mathrm{mst} 187$.

(57) Hurst, A. Biosynthesis of the Antibiotic Nisin by Whole Streptococcus Lactus Organisms. J. Gen. Microbiol. 1966, 44 (2), 209-220, DOI: 10.1099/00221287-44-2-209.

(58) Miles, A. A.; Misra, S. S.; Irwin, J. O. The Estimation of the Bactericidal Power of the Blood. J. Hyg. 1938, 38 (6), 732-749, DOI: 10.1017/S002217240001158X. 
(59) Khandare, J.; Minko, T. Polymer-Drug Conjugates: Progress in Polymeric Prodrugs. Prog. Polym. Sci. 2006, 31 (4), 359-397, DOI: 10.1016/j.progpolymsci.2005.09.004.

(60) Shen, J.; Shi, M.; Yan, B.; Ma, H.; Li, N.; Hu, Y.; Ye, M. Covalent attaching protein to graphene oxide via diimide-activated amidation. Colloids and Surfaces B: Biointerfaces 2010, 81 (2), 434-438, DOI: 10.1016/j.colsurfb.2010.07.035.

(61) Lin, X.; Shen, X.; Zheng, Q.; Yousefi, N.; Ye, L.; Mai, Y. W.; Kim, J. K. Fabrication of HighlyAligned, Conductive, and Strong Graphene Papers Using Ultralarge Graphene Oxide Sheets. ACS Nano 2012, 6 (12), 10708-10719, DOI: 10.1021/nn303904z.

(62) Yang, D.; Velamakanni, A.; Bozoklu, G.; Park, S.; Stoller, M.; Piner, R. D.; Stankovich, S.; Jung, I.; Field, D. A.; Ventrice Jr, C. A.; Ruoff, R. S. Chemical Analysis of Graphene Oxide Films After Heat and Chemical Treatments by X-Ray Photoelectron and Micro-Raman Spectroscopy. Carbon 2009, 47 (1), 145-152, DOI: 10.1016/j.carbon.2008.09.045.

(63) Huang, J. F.; Zhong, J.; Chen, G. P.; Lin, Z. T.; Deng, Y.; Liu, Y. L.; Cao, P. Y.; Wang, B.; Wei, Y.; Wu, T.; Yuan, J.; Jiang, G. B. A Hydrogel-Based Hybrid Theranostic Contact Lens for Fungal Keratitis. ACS Nano 2016, 10 (7), 6464-6473, DOI: 10.1021/acsnano.6b00601.

(64) Liu, Y.; Vincent Edwards, J.; Prevost, N.; Huang, Y.; Chen, J. Y. Physico- and Bio-Activities of Nanoscale Regenerated Cellulose Nonwoven Immobilized with Lysozyme. Mater. Sci. Eng., C 2018, 91, 389-394, DOI: 10.1016/j.msec.2018.05.061.

(65) Zhou, C.; Li, P.; Qi, X.; Sharif, A. R. M.; Poon, Y. F.; Cao, Y.; Chang, M. W.; Leong, S. S. J.; Chan-Park, M. B. A Photopolymerized Antimicrobial Hydrogel Coating Derived from Epsilon-Poly1-Lysine. Biomaterials 2011, 32 (11), 2704-2712, DOI: 10.1016/j.biomaterials.2010.12.040.

(66) Jahandideh, H.; Ganjeh-Anzabi, P.; Bryant, S. L.; Trifkovic, M. The Significance of Graphene Oxide-Polyacrylamide Interactions on the Stability and Microstructure of Oil-in-Water Emulsions. Langmuir 2018, DOI: 10.1021/acs.langmuir.8b02288.

(67) Kumar, A.; Behera, B.; Ray, S. S. Microwave-Assisted Surface-Initiated Redox Polymerization of Acrylamide with Functionalized Graphene Oxide for Aqueous Lubricant Additive. RSC Adv. 2015, 5 (49), 39474-39481, DOI: $10.1039 / \mathrm{c} 5 \mathrm{ra} 05623 \mathrm{c}$.

(68) Ellison Iii, R. T.; Giehl, T. J. Killing of Gram-Negative Bacteria by Lactoferrin and Lysozyme. J. Clin. Invest. 1991, 88 (4), 1080-1091, DOI: 10.1172/JCI115407.

(69) Masschalck, B.; Van Houdt, R.; Van Haver, E. G. R.; Michiels, W. C. Inactivation of GramNegative Bacteria by Lysozyme, Denatured Lysozyme, and Lysozyme-Derived Peptides Under High Hydrostatic Pressure. Appl. Environ. Microbiol. 2001, 67 (1), 339-344, DOI: 10.1128/AEM.67.1.339-344.2001.

(70) Khan, A.; Vu, K. D.; Riedl, B.; Lacroix, M. Optimization of the Antimicrobial Activity of Nisin, Na-EDTA and pH Against Gram-Negative and Gram-Positive Bacteria. LWT-Food Sci. Technol. 2015, 61 (1), 124-129, DOI: 10.1016/j.lwt.2014.11.035. 
(71) Stevik, T. K.; Aa, K.; Ausland, G.; Hanssen, J. F. Retention and Removal of Pathogenic Bacteria in Wastewater Percolating Through Porous Media: A Review. Water Res. 2004, 38 (6), 1355-1367, DOI: $10.1016 /$ j.watres.2003.12.024. 


\section{Graphical Abstract}

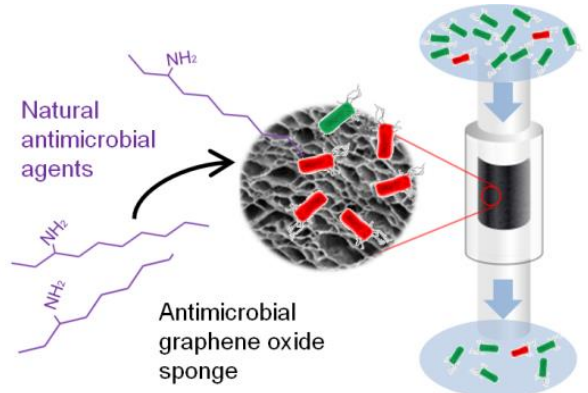

